\title{
دور الهندسة المالية الاسلامية في معالجة الأزمات المالية
}

\author{
The role of Islamic financial engineering in dealing with financial crises
}

\author{
تاريخ الاستلام : 2019/05/22؛ تاريخ القبول : 2020/04/04
}

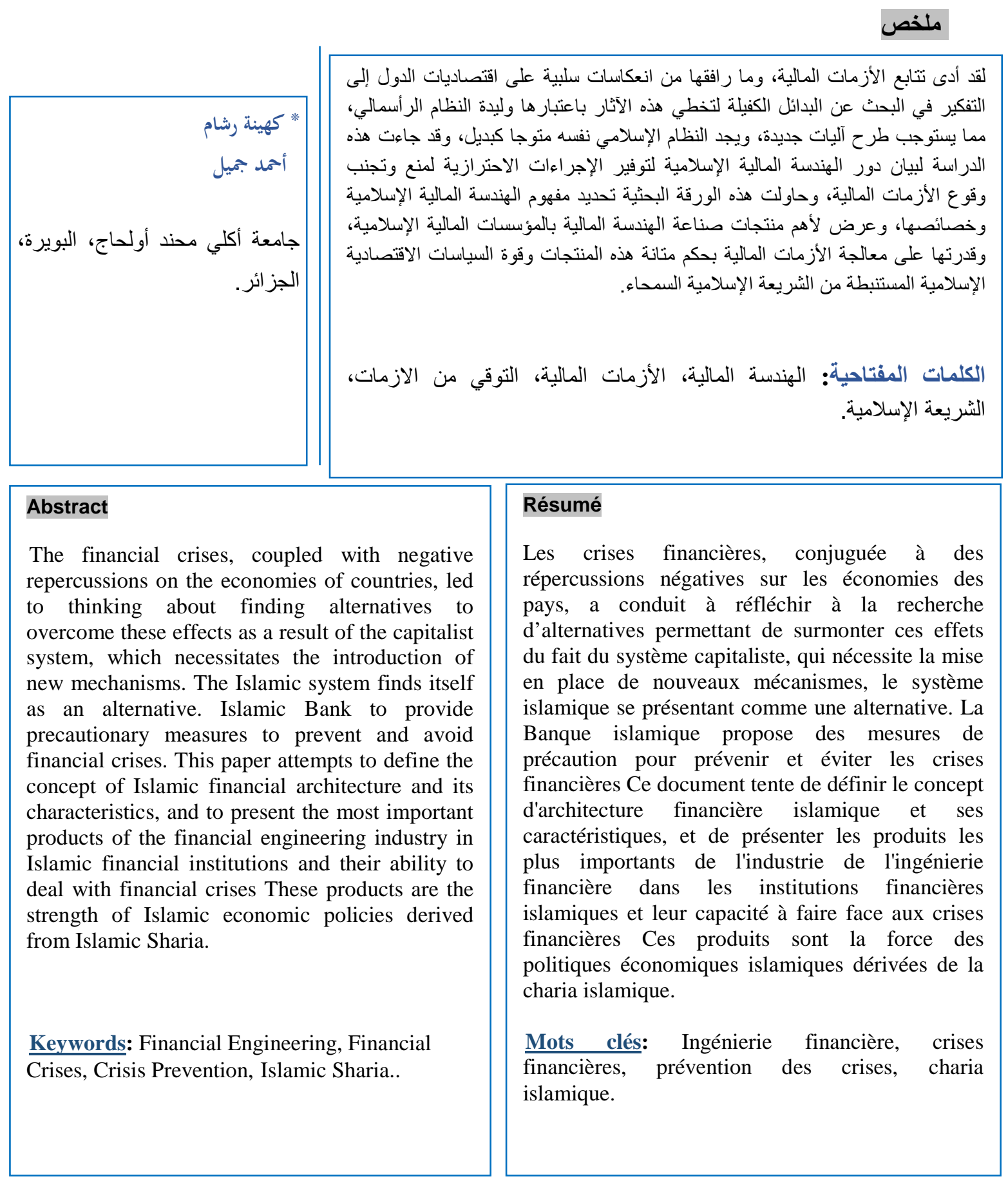

* Corresponding author, e-mail: rechamkahina@gmail.com 


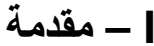

لقد شكلت التقلبات الكبيرة و غير المتوقعة في الأسعار بما فيها أسعار السلع وأسعار

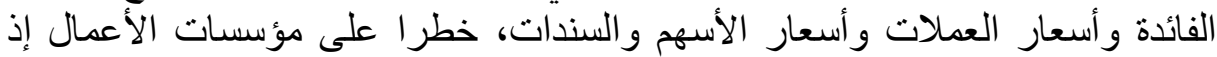

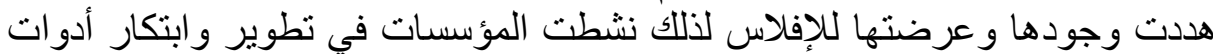

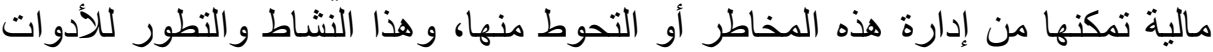

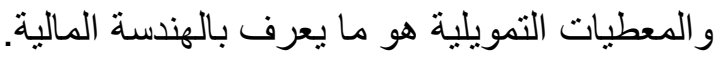

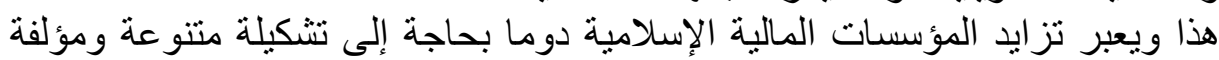

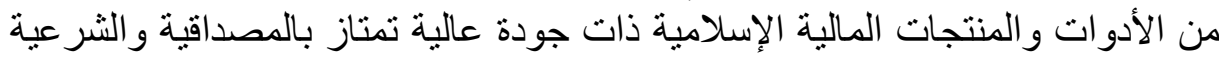

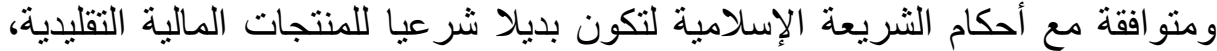

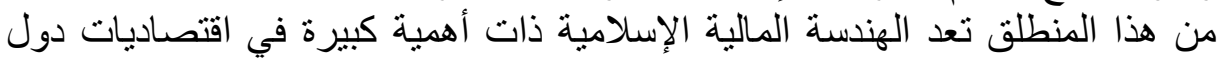

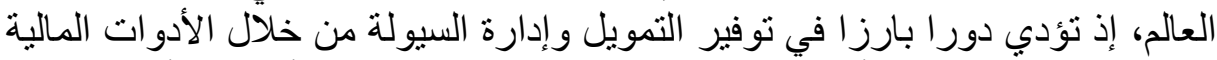

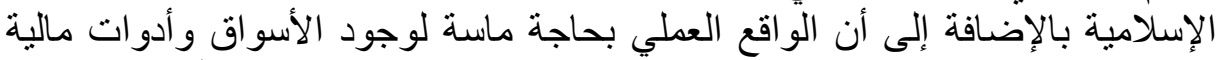
مضبوطة بالثريعة الإسلامية وذات كفاءة عالية وقادرة الإنى على مواجهة الأزمات وتفعيل النشاط الاقتصادي. ومن هنا تظهر معالم إثكالية البحث على التهى النحو النالي:

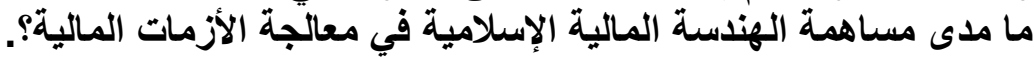

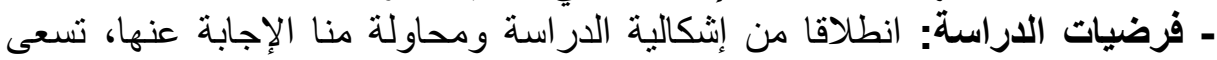
دراستنا هذه لاختبار الفرضيات الطرات التالية: - ينسبب مخطر النظام في حدوث الازئن الإمات المالية؛ - تعتبر الصكوك الاسلامية من أهم أنواع الأدوات الماتهة المتعامل بها في الهندسة المالية

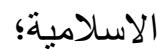
ـ السبيل الوحيد لتجنب الازمات الاقتصادية هو التمويل الاسلامي.

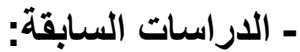

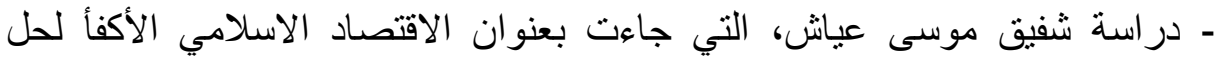

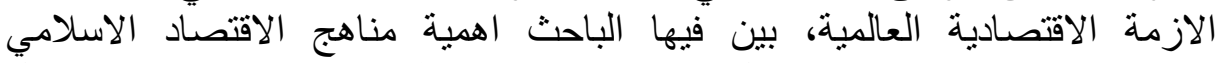

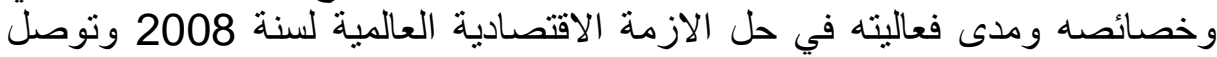

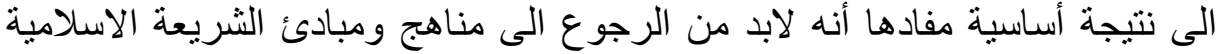
لاستنباط الانظمة والقوانين التي تسير الانظمة المالية الحديثة، نظرا لتانئ لتفاقم الآثار السلبية لقو انين ولوائح الانظمة الوضئة الوضعية.

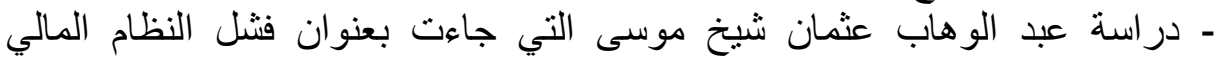

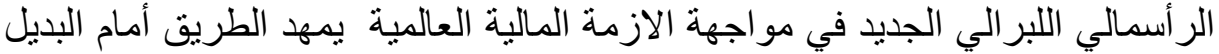

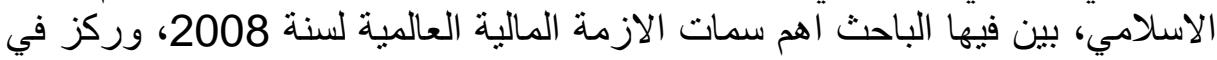

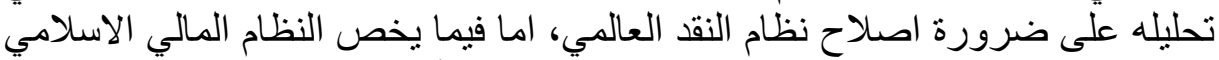

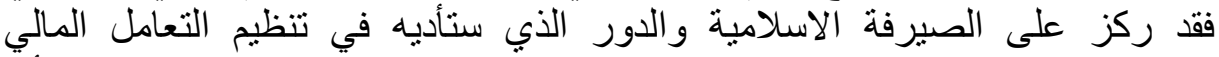

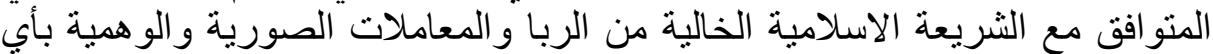

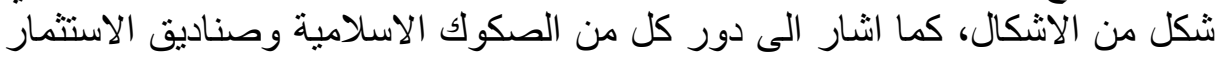

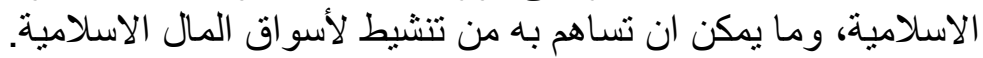

وللاججابة على الإثكالية ارتأينا تناول المحاور التالية :

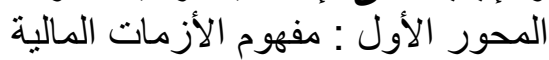

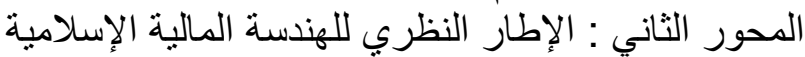
المحور الثالث: الهندسة المالية الاسلامية وتجنب الأزمات المالية الإلية 
1-II

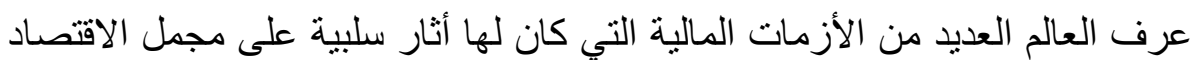

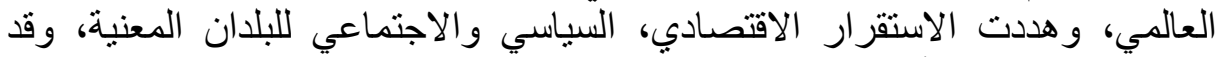

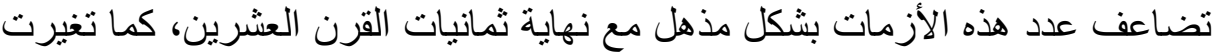

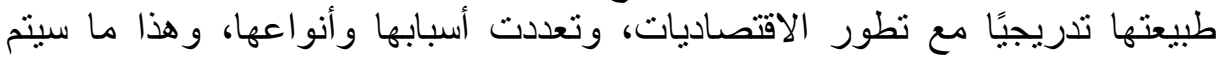

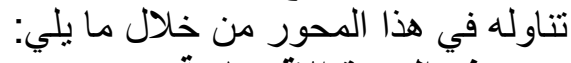
ـ ت تعريف الاورة الاقتصادية

لقد شكلت الدورة الاقتصادية منذ قرنين أحد الخصائص الأصن الأساسية التي ميزت التصائ التطور

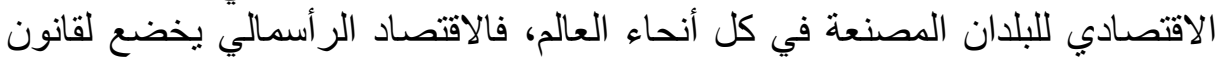

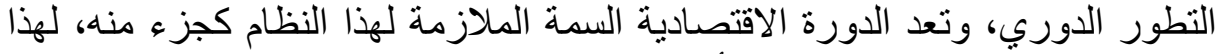

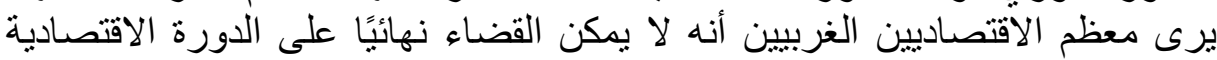
إنّما التخفيف من من آثنار ها.

يشير مصطلح الدورة الاقتصادية إلى تكر ار ظاهرة معينة، حيث تعرف على أنها: (1)

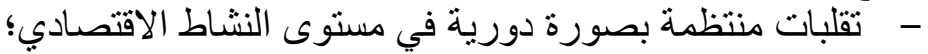

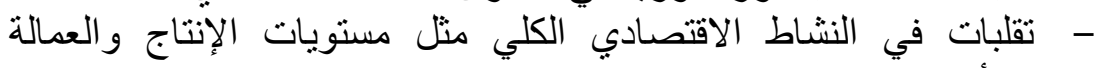

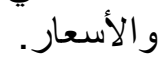

ويعرف Pagon (1997م)، الدورة الاقتصادية بأنها: لاذللك التتابع بين مرحلة القمة (Pikes) و القاع (Creux) أو أنها تلك التقلبات التي تؤثر على مجمل النشاط الاقتصادي؛؛) (2) كما عرفت الدورة الاقتصادية على أنها: لاتأرجح في مجموع الناتج القومي و التو الدخل

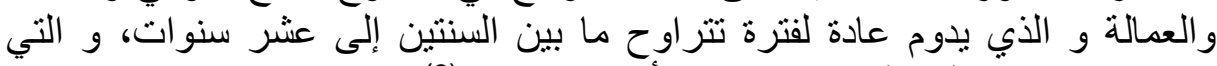

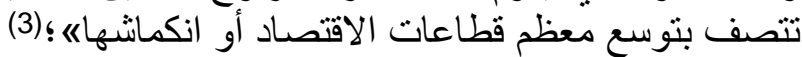

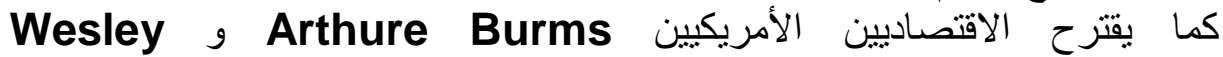
Research

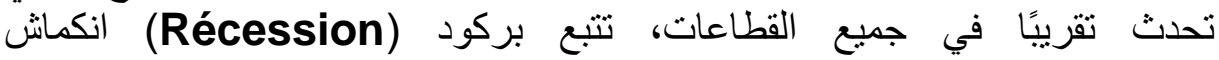
(Contraction)

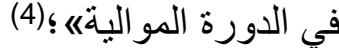

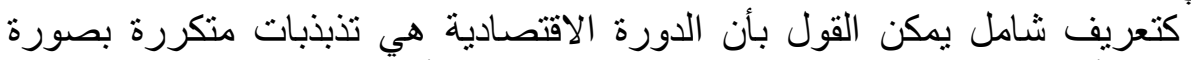

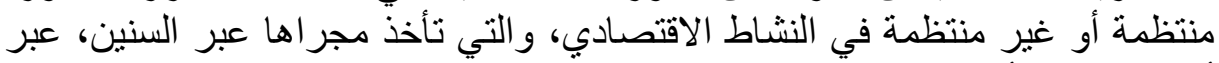

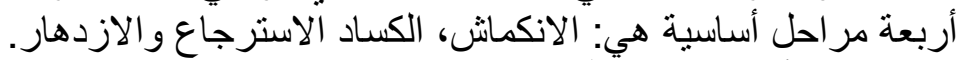

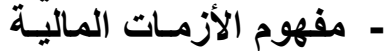
نحاول إدراج بعض التعاريف للأزمات المالية بهالية بهدف التوصل إلى معرفة أين يكمن

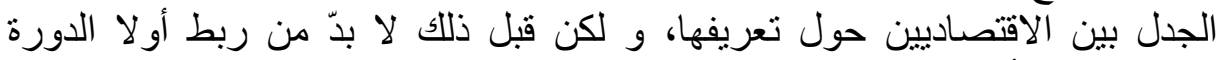

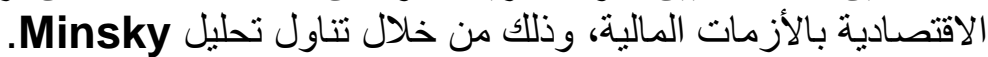

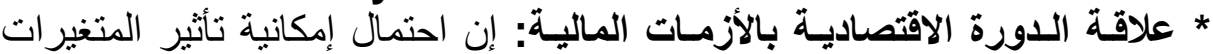

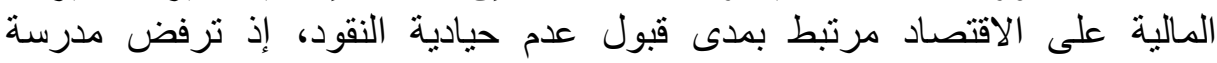

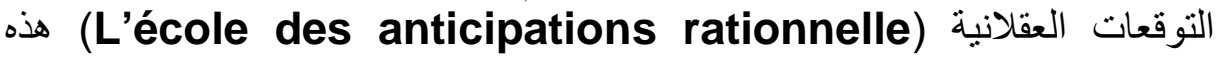
الحالة، في حين تتص نظرية Modigliani-Miller في عام 1958م، على عدم

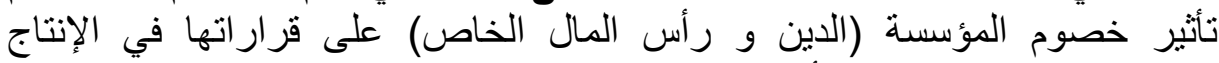

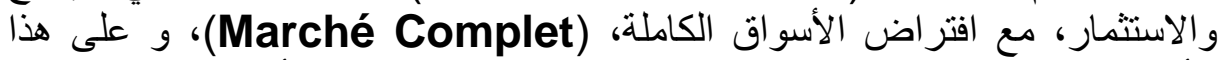
الأساس عمّم Fama هذه النتيجة لـ Miller، و الإنة بين أن الهياكل المالية 
ليس لديها أي تأثير على التوازن الاقتصادي ومن (Structures Financiers)

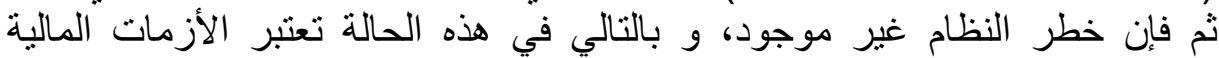

مستحيلة. (5) فئن

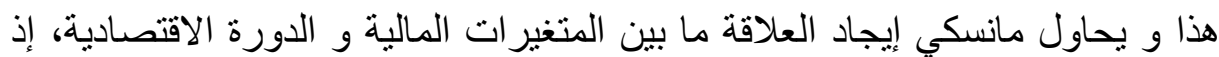

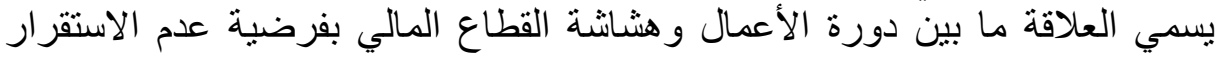

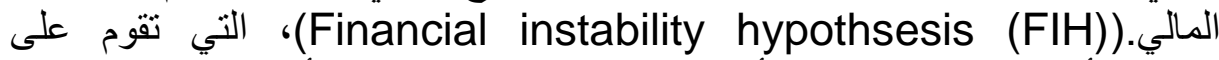

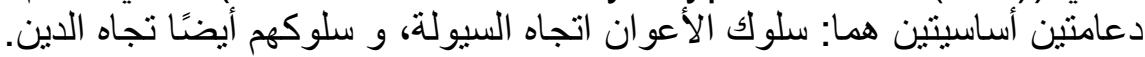

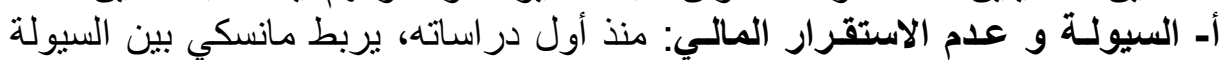

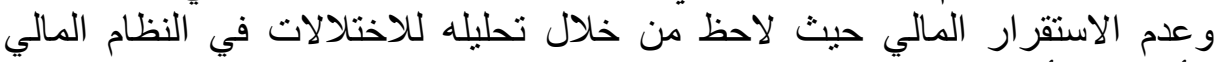

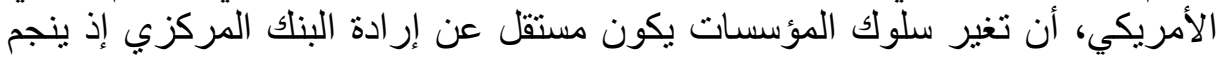

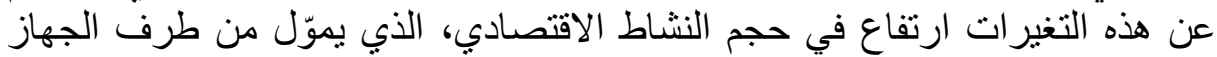

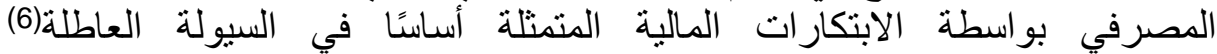
(Liquidité oisive)

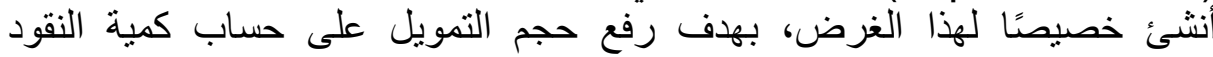

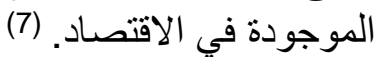

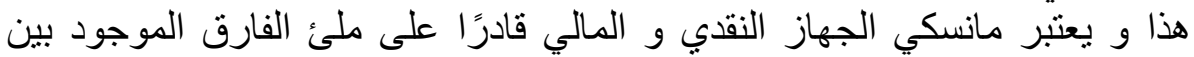

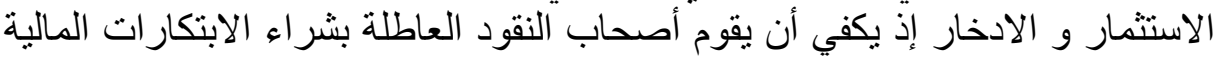

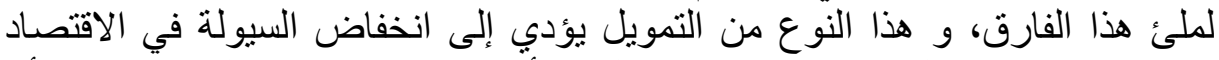

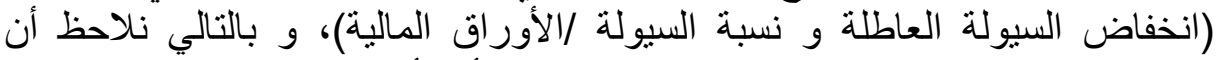

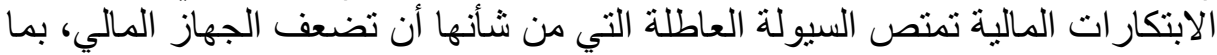

أن حجم الالتزامات ترتفع رغم بقاء كات كمية النقود ثابتة.

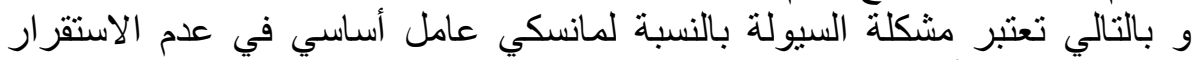

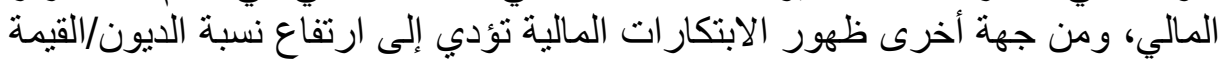
الصافية و التي تؤدي بدور ها إلى مشئ مشكلة ملاءة الدين.

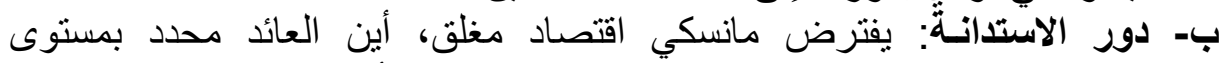

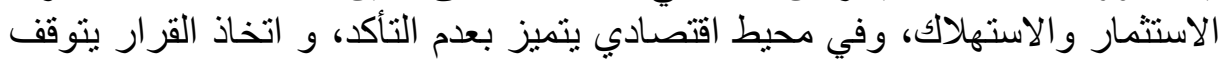

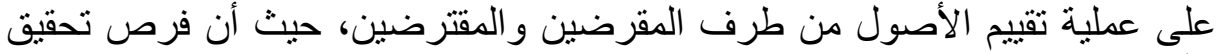

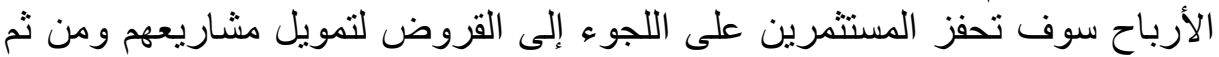

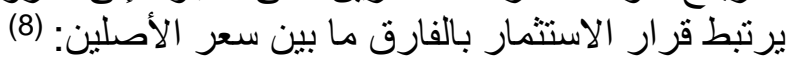

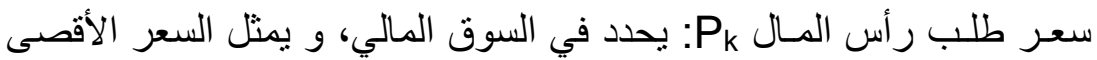

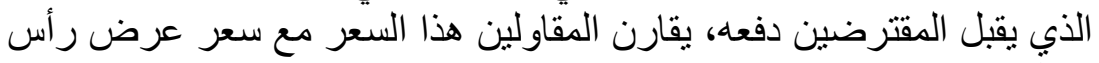

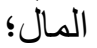

$$
\text { • سعر عـرض رأس المـال Pi: يمثل سعر السلع المستثمرة. }
$$

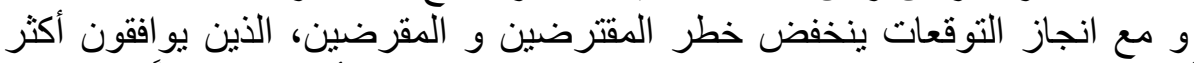

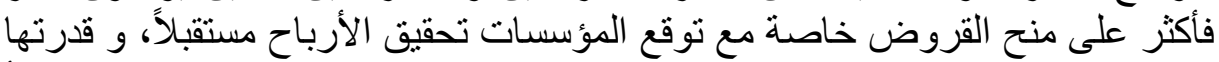

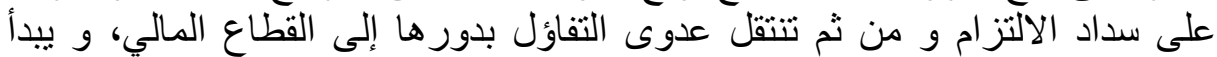

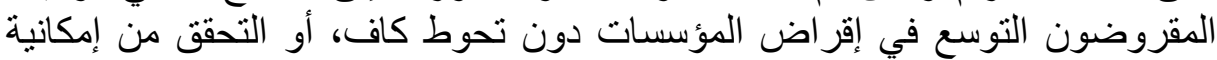

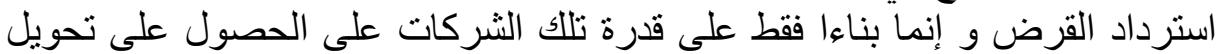

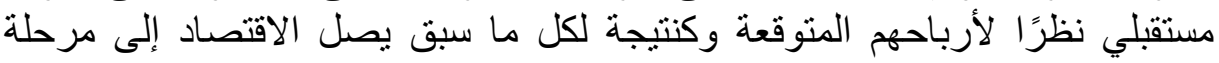

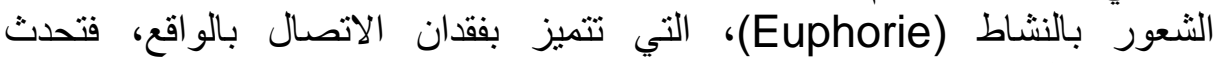

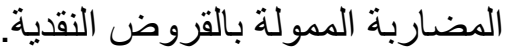

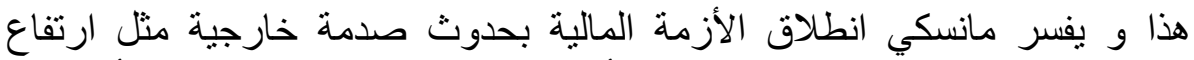

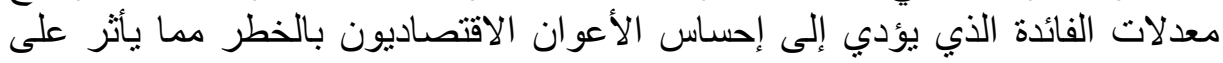


قابليتهم للإقراض، و بالتالي هذا الأخير يؤثر بدوره على قدرة معظم الأعوان

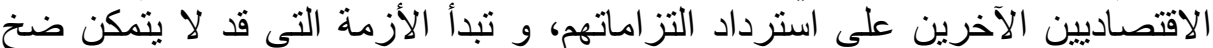

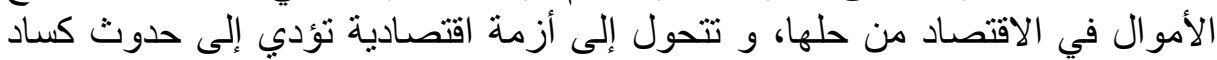

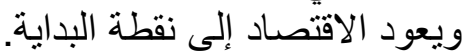

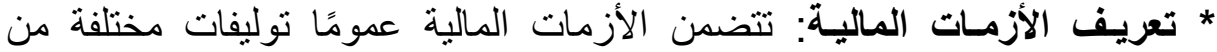
المشاكل النقدية و المصرفية ومشاكل الديون، و ولى هذى هذا الأساس فقد تعددت مفاهيمها

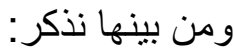

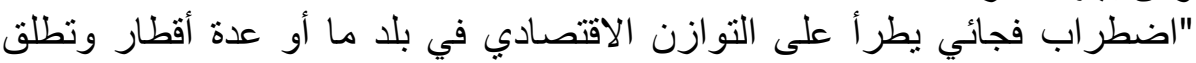

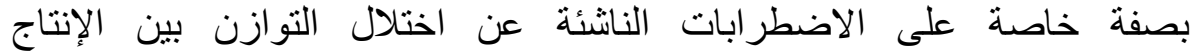

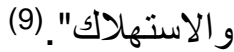

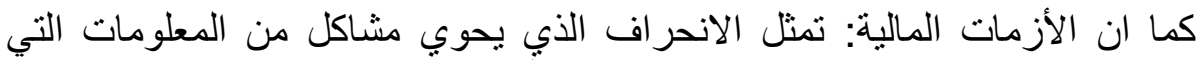

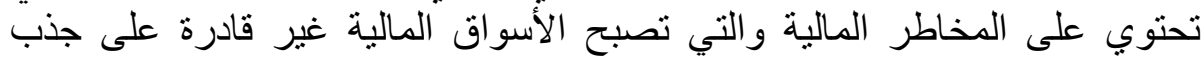

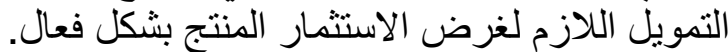

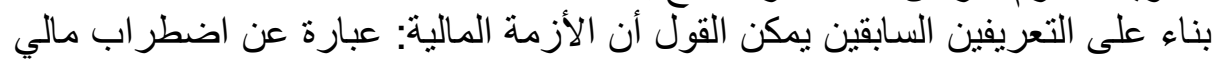

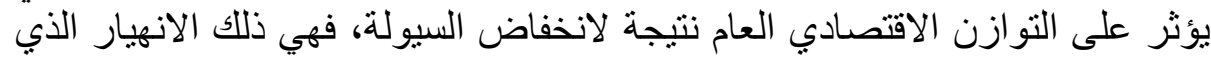

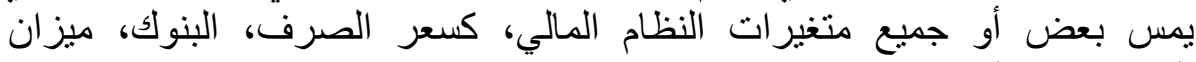
المدفو عات و البور المية.

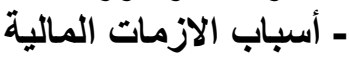

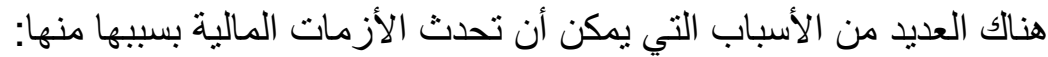

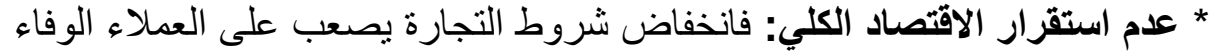

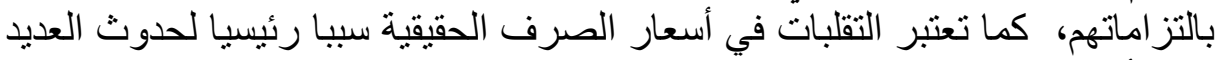

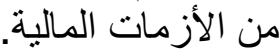
* فقاعة المضاربة: الارتفاع المستمر لسعر الأصل مما يؤدي إلى فرق كبير ما بين

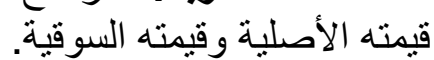

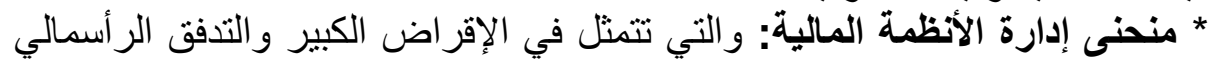

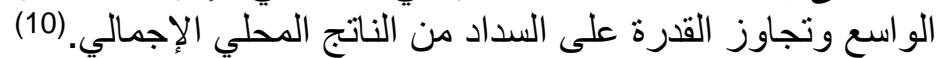
* عدم تماثل المعلومات: مما يترتب على التى ذلك أن الطرف الإن الآخر لن يستطيع تقييم

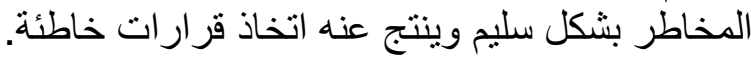

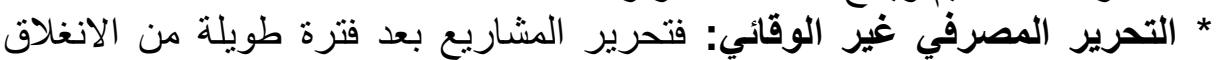

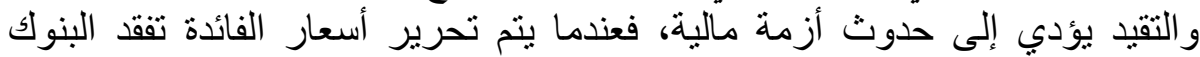

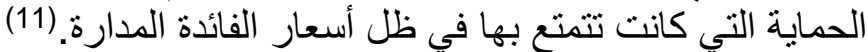

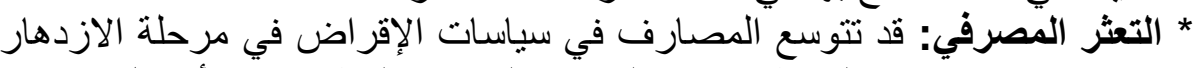

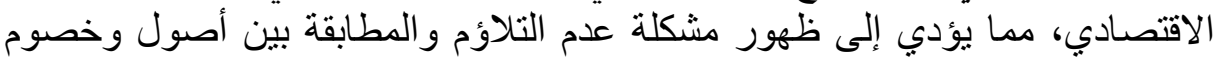

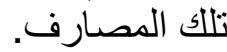

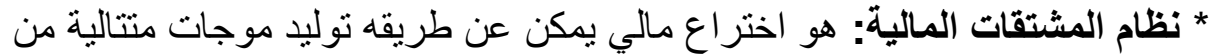

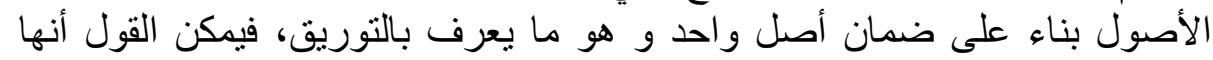
معاملات ورقية شكلية تقوم على الاحتمالات ألات الهات

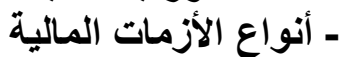
يمكن التمبيز ما بين ألازمات المبلة أربة أنواع من الأزمات المالية وهي:

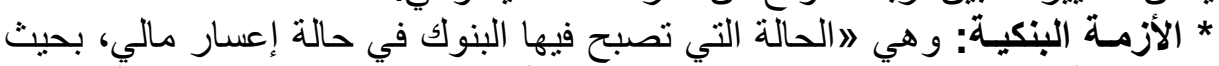

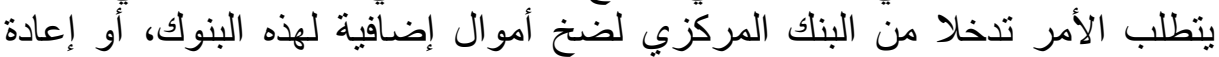

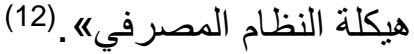
* أزمـة سعر الصـرف: في حالة حصول الخفاض كبير في قيمة الصرف وف وأو إعلان

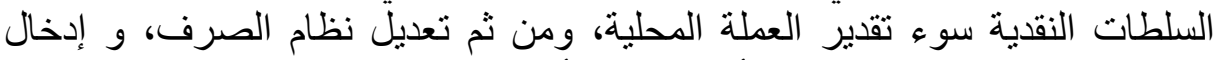

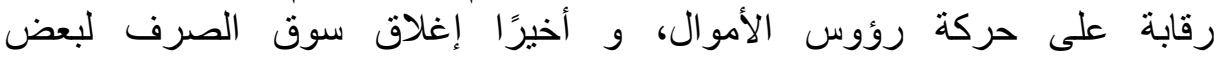




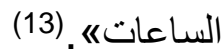

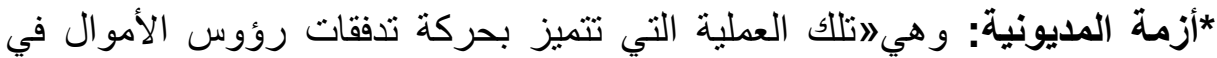

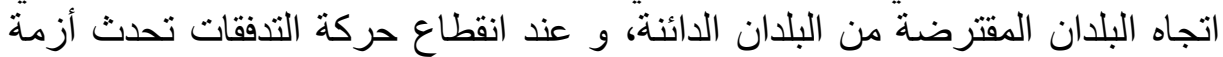

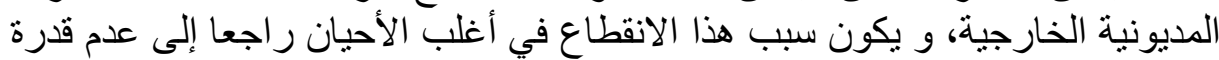
البلد المدين على الوفاء بالتز اماته الخارجيةها. (14)

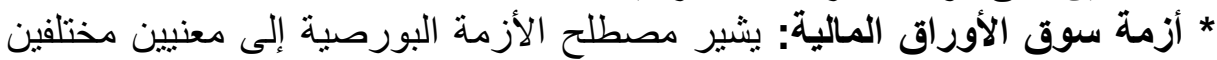

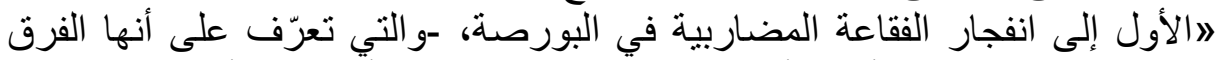

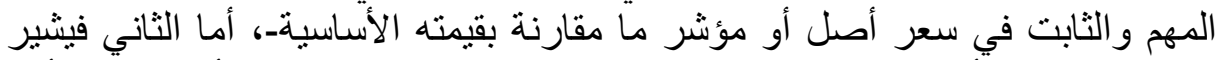

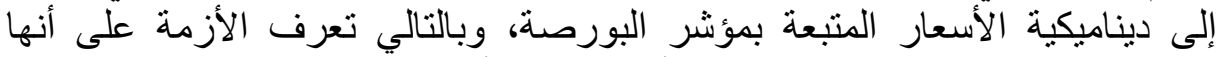

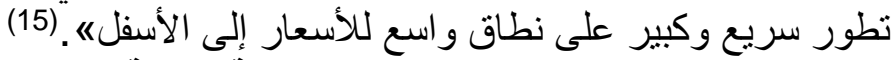

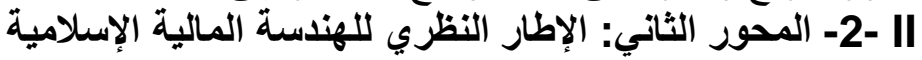

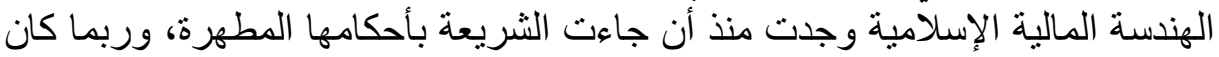

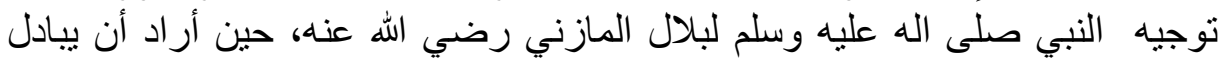

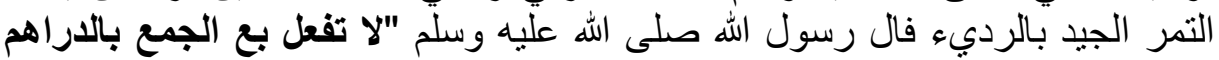

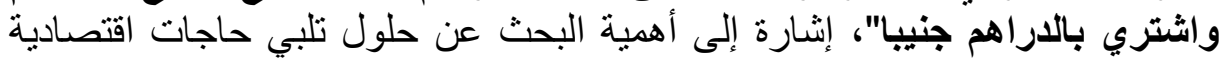
دون الإخلال بالأحكام الثر عية.

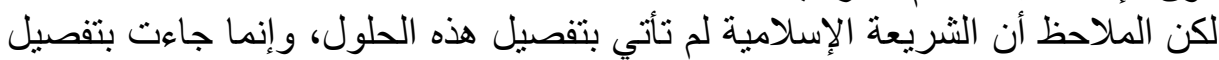

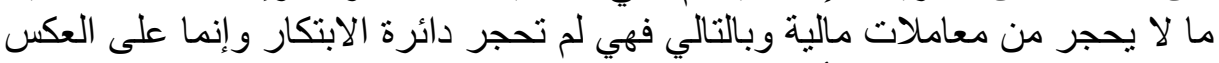

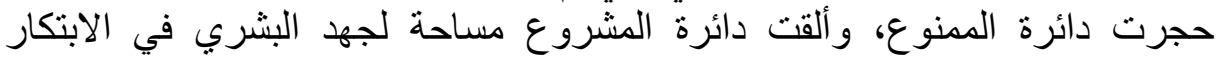

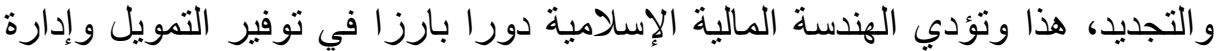

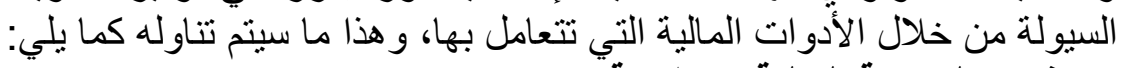

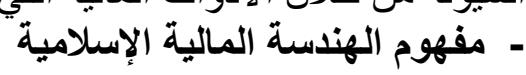
سيتم تناول كل من تعريف ، خصائص ومبادئ الإسية الهندسة المالية الإسلامية: * تعريف الهندسة المالية الإسلامية: من بينها نذائكر:

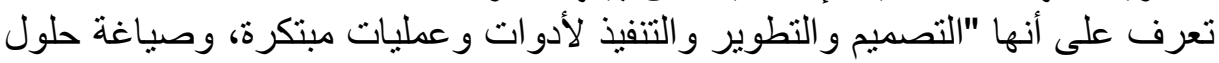

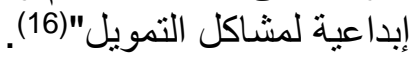

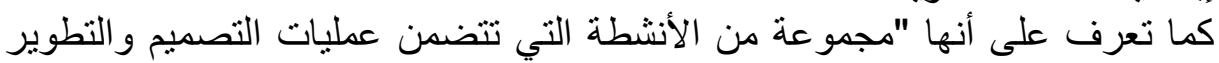

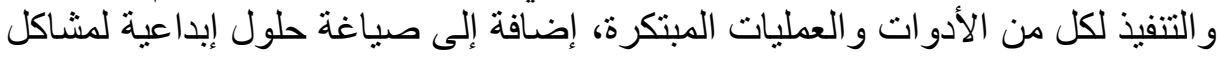

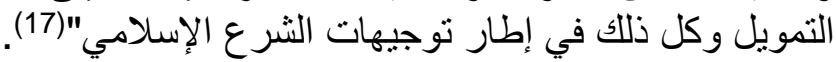

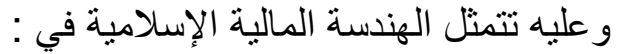

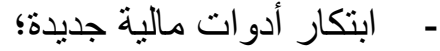

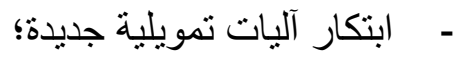

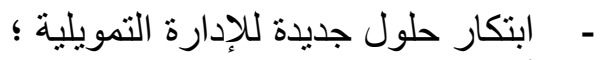

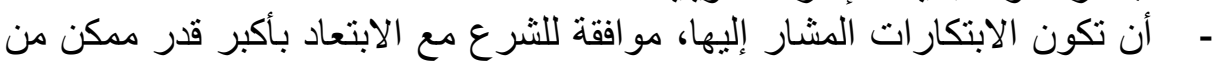

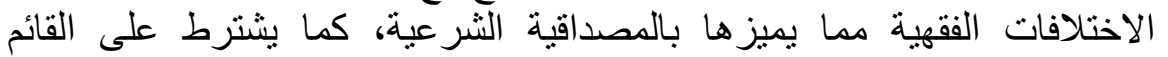

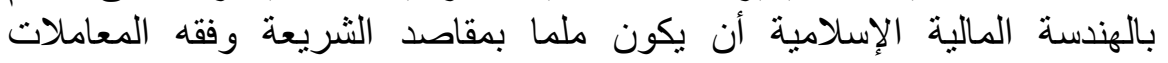

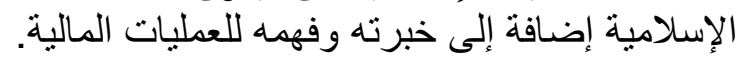
* خصائص الهندسة المالية الإسلامية:

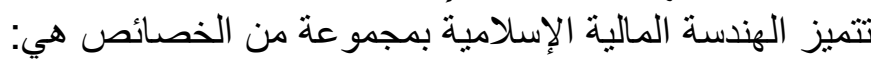

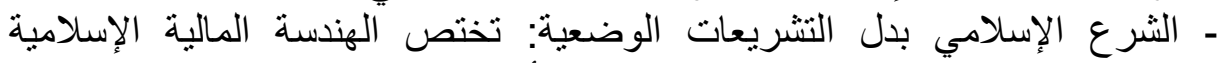

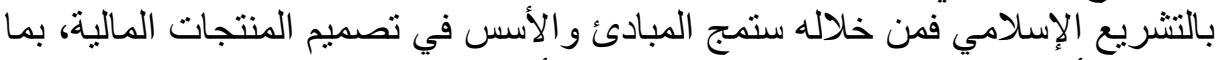

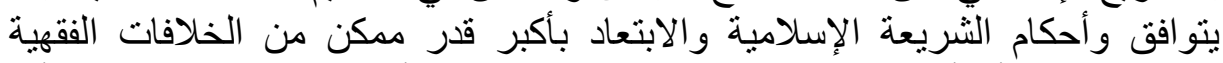

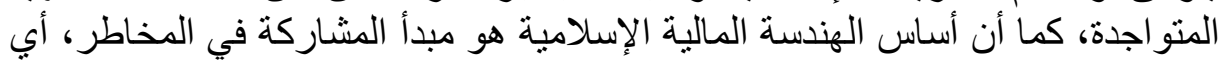


تقاسم الأعباء بين مختلف الأطر اف وليس مبدأ المخاطر وتحويلها لأطر اف أخرى. ـ الكفاءة الاقتصادية: تتميز الهندسة المالية الإسلامية بالإضافة إلى المصداقية الثافية الثرعية

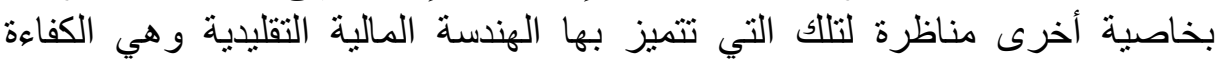

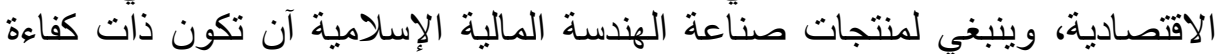

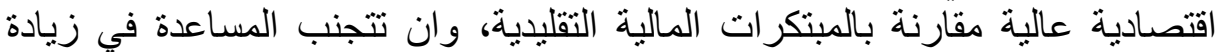

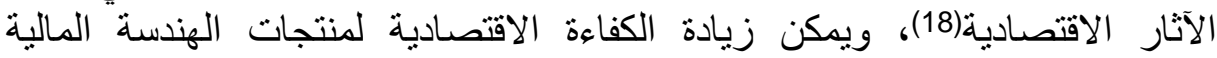

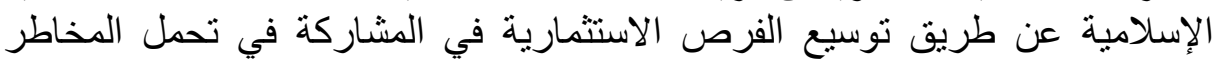

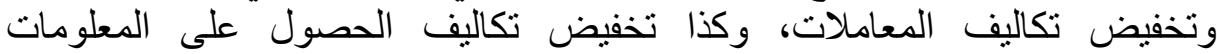
و ومو لات الوساطة والسمسرة(19). - الابتكار الحقيقي بدل التقليد: يعتبر التنوع التوالية المتوفر في المنتجات المالية الإسلامية

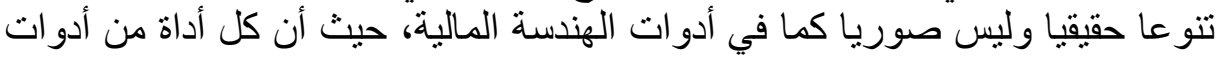

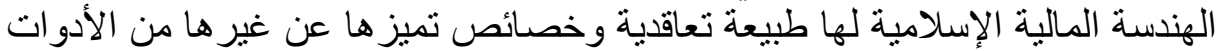

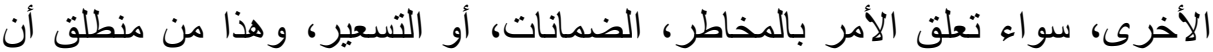

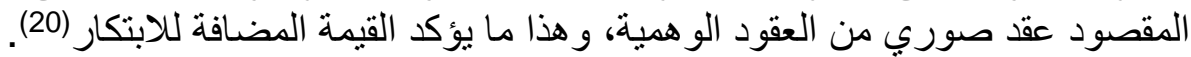

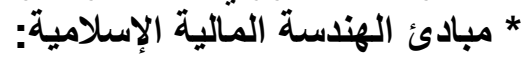
يوجد أربعة مبادئ يلزم بتطبيقها القائمون بالهندسة المالية الإسلامية من اجل ضمان الإن

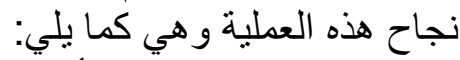

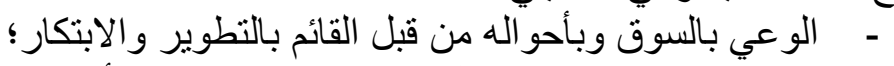

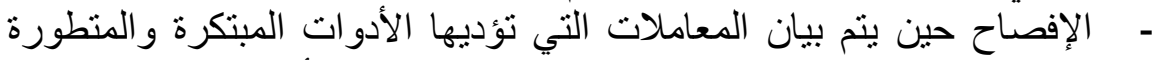

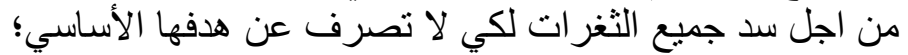

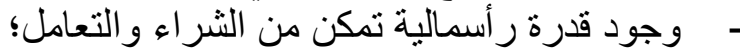

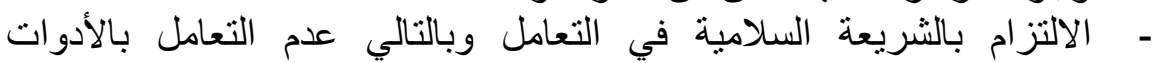

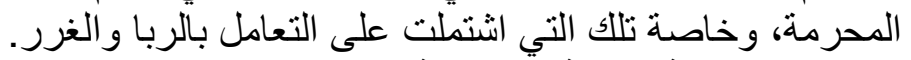

-

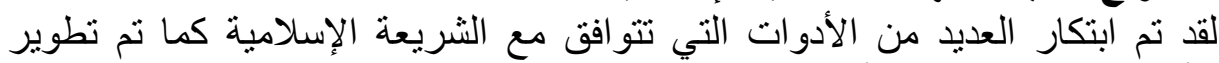

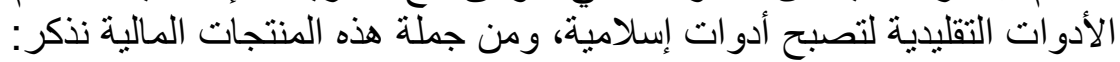

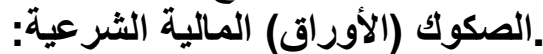

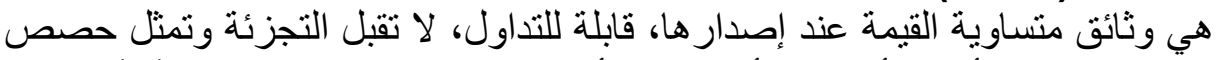

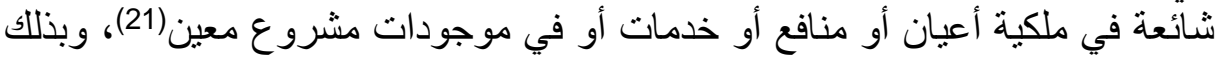

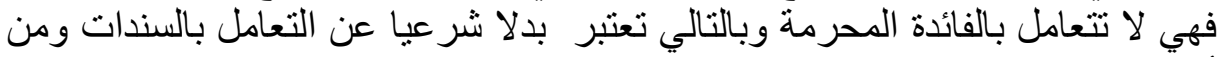

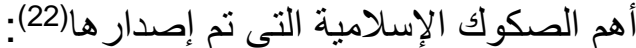

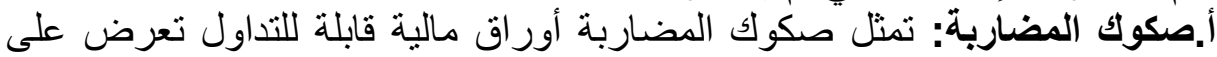

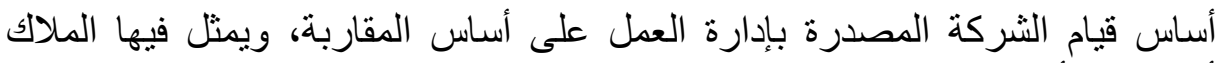

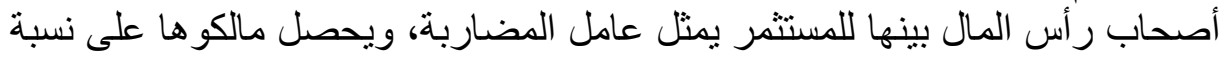

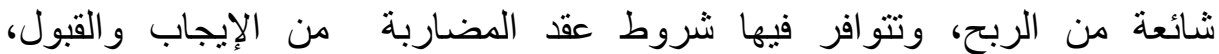

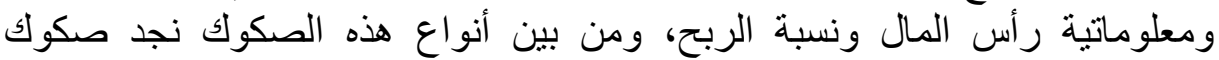

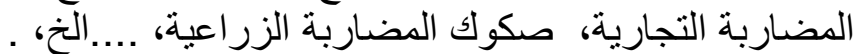

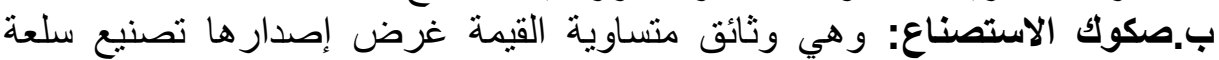

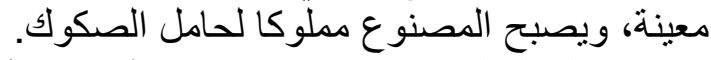
ج. صكوك السلم: هي وثائق متساوية القيمة تمثل ملكية شائعة في رأس المال السلم

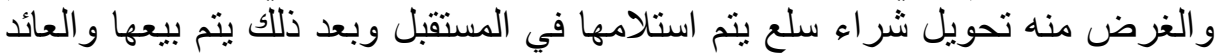

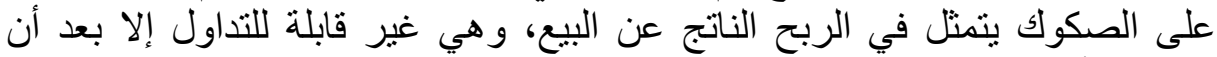

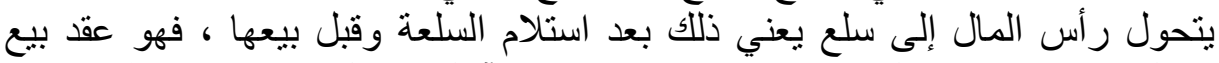

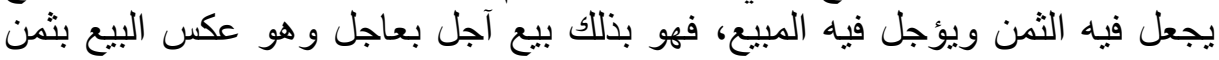




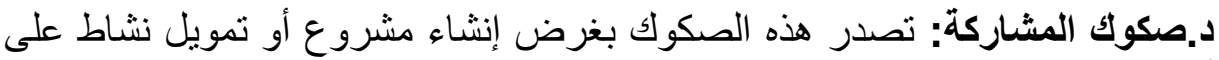

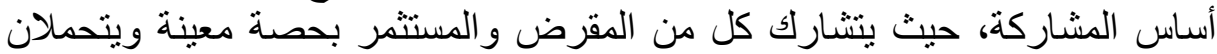

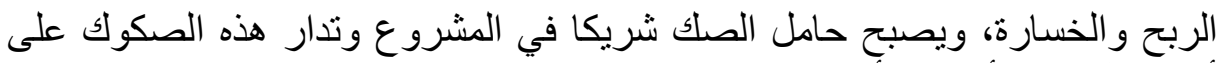

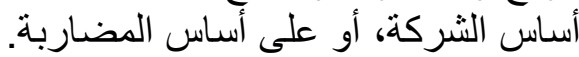

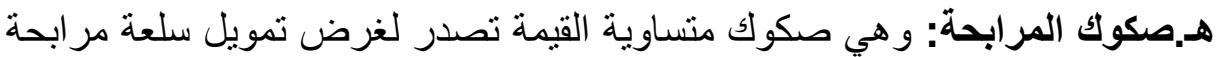

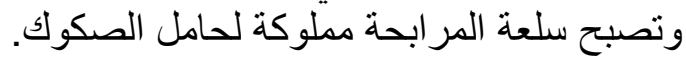

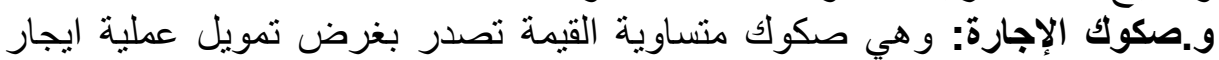

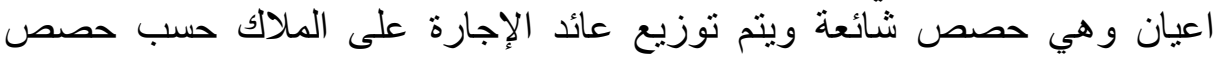
ملكيتهم وهي صكوك هو قابلة للتداول.

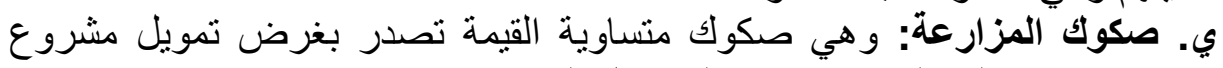
زر اعي ويصبح لحامليها حصة في في الحصول فيكا الناتج.

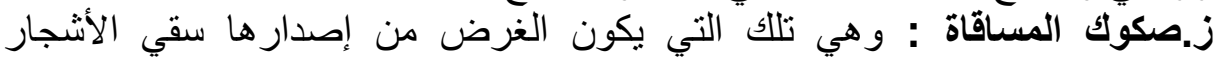

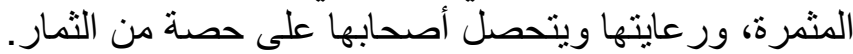

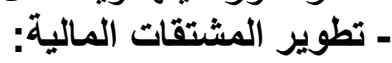

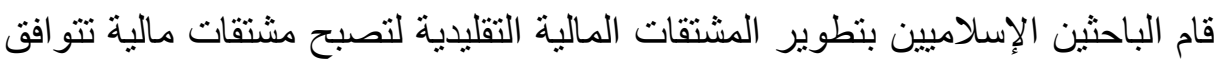
مع الثريعة الإسلامية، بالتالي يمكن تداولها من غير حرج وذللك من خلال تكييف فقهي لها كالتالي (23): أ.التكييف الفقهي لعقود الخيارات: يمكن اعتبار عقد خيار الثراء بيع العربون التهائ وهو

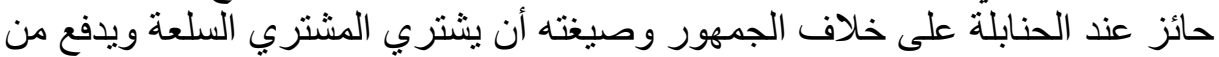

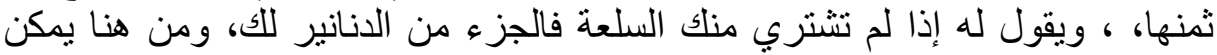

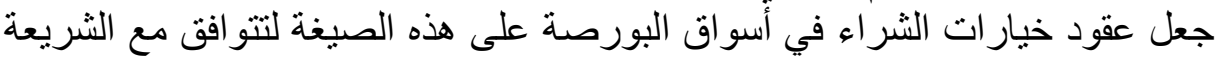

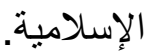

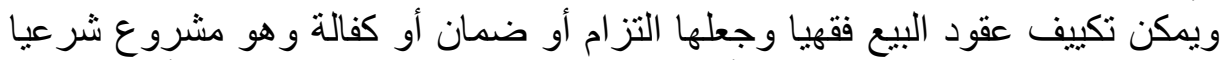

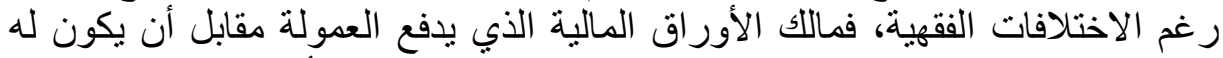

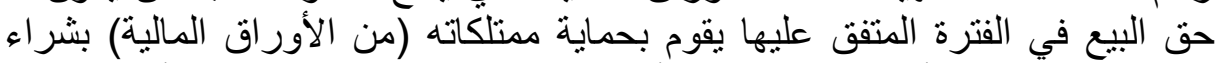

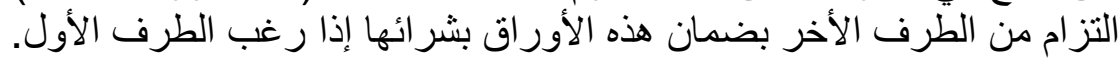

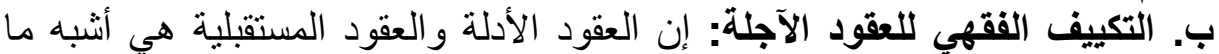

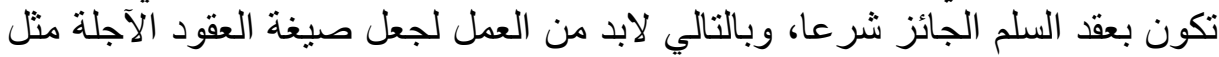

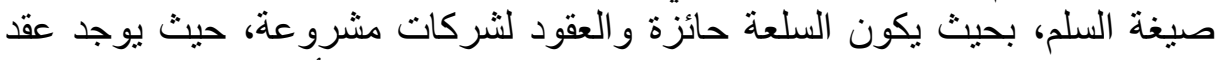

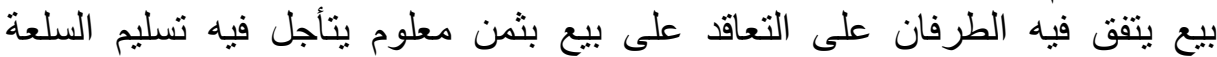

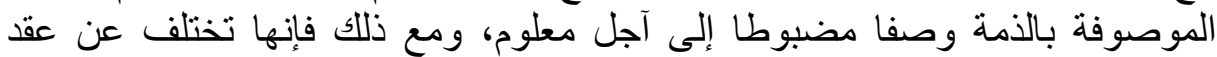

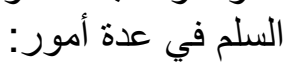

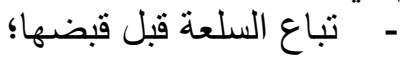

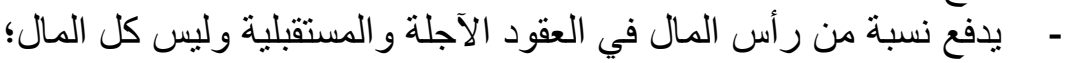

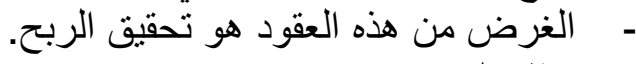

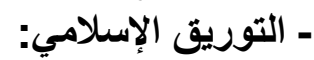

يعني مصطلح التوريق "الحصول على على الأموال استنادا إلى الديون المصرفية القائمة

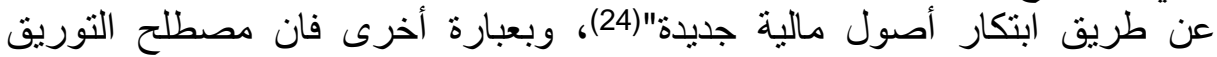

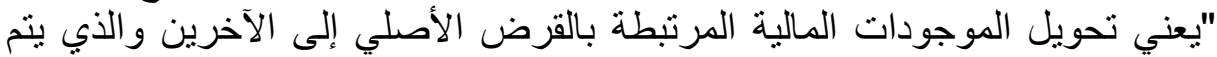

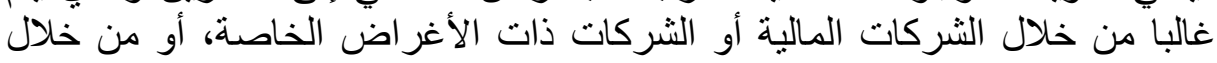

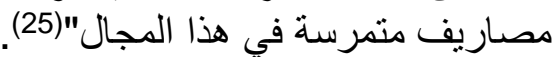

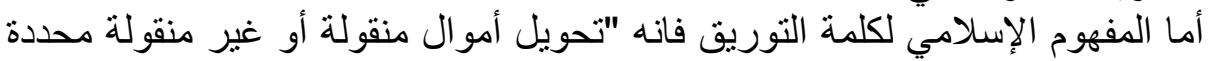
إلى أداة مالية محددة مفصولة الإمة ومحددة المدة ذات عائد معين ولها لها وصف التف محدد، 
وقد كان المسلمون يسمون هذا النوع بالموارقة وهي استعمال الصكوك مقابل الدراهم الدما

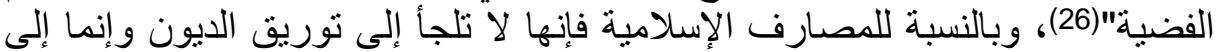

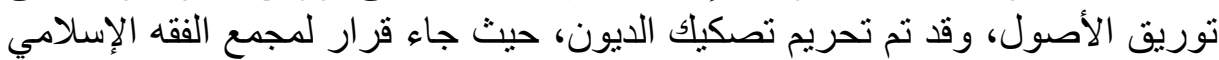

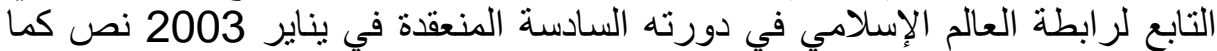

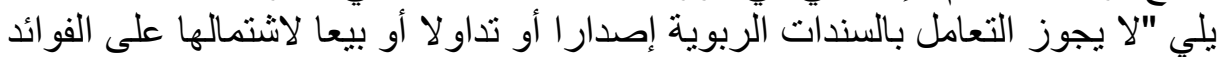

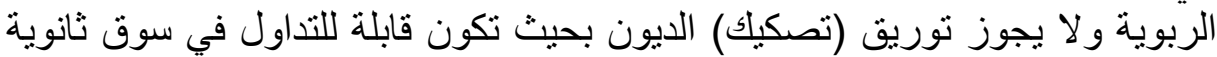

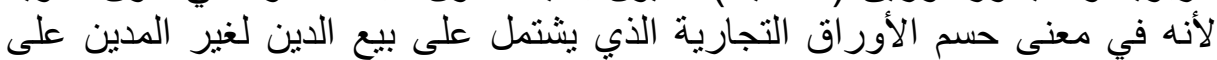

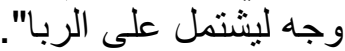

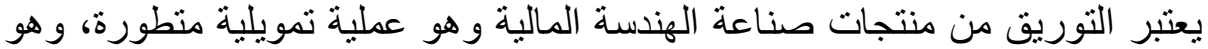

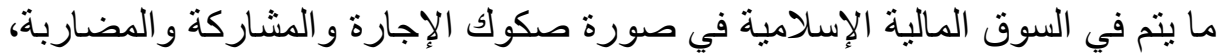

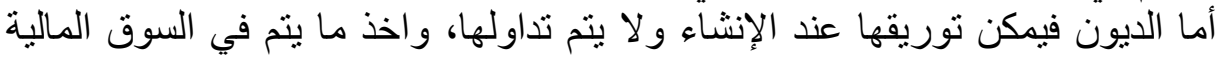
الإسلامية بصكوك المر ابحة و السلم و الاستصناع.

- بعض نماذج التطبيقية لإصدارات أدوات الهندسة المالية الإسلامية

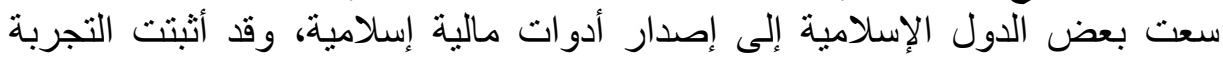
العملية نجاحا هائلا في كثير من الدول الإسلامية، ونستعرض هنا بشكل مختصر

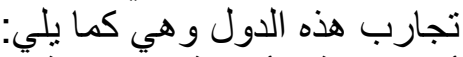
أـ المملكة الأردنية الهاشمية: تعد الهمانية المملكة الأردنية الهاشمية الأولى تأصبلا لسندات

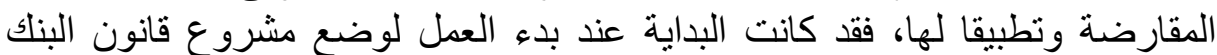

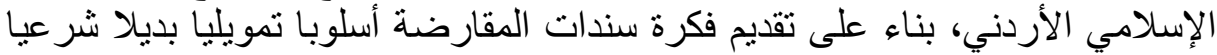

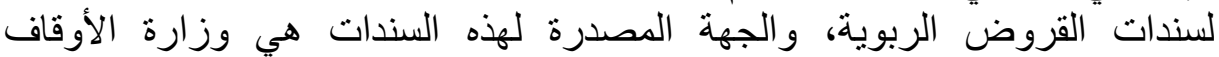
و الثؤون و المقدسات الإسلامية في الأردن. ب- تركيا: صدرت في تركيا عام 1984 صكوك الك مشاركة بمبلغ 200 مليون دولار ومخصصة لتمويل بناء جسر معلق على مضيق البوسفور و لاقيى هذا الإصدار قبو لإنا

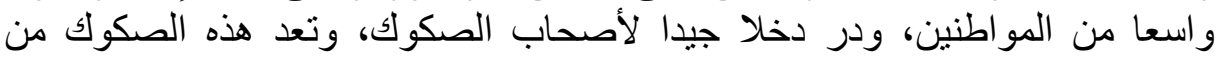

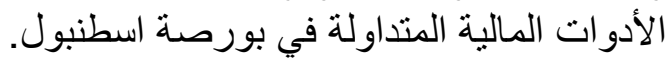
ج- ماليزيا: أصدرت الحكومة الماليزية صكوك التك حكومية متوافقة مع أحكام الثريعة الإسلامية، تدعى شهادات الاستثمار الحكومي وذلك عام 1983،وهية هنالك الصكوك

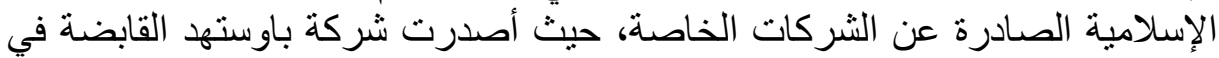

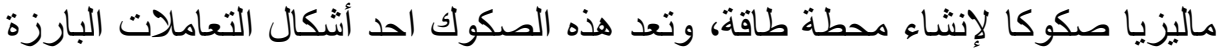

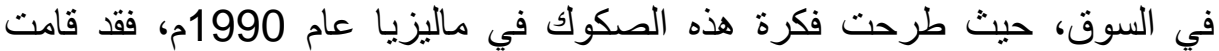

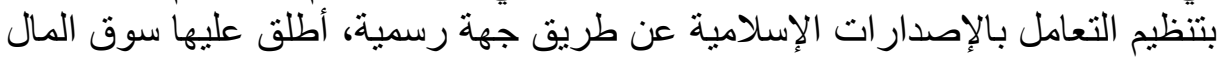

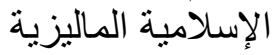
دـ السودان : قام المصرف المركزي السوداني في عام 1999م، بإصدار شهادات مشاركة المصرف المركزي (شمم)، وهي وثنية إسلامية قابلة للتداول، والهرف

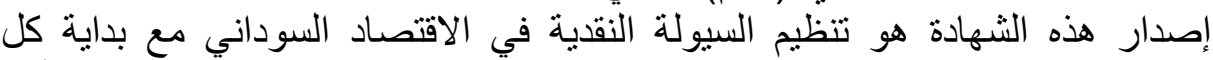

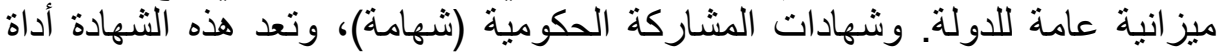
مالية إسلامية شرعية تقوم على أساس المشاركة بين الحكومة والمستثمرين، ويتحمل

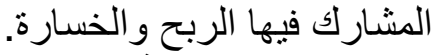

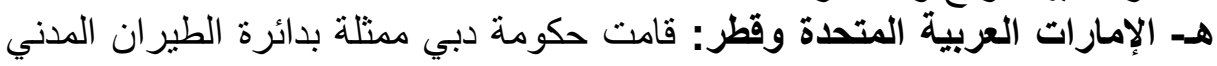

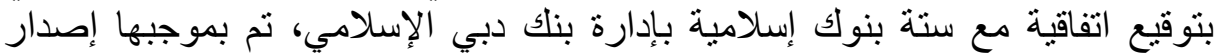
صكوك إجارة بقيمة بليون دولار أمريكي، تم تغطيتها بالكامل، وفي قطر فقد أدار كل

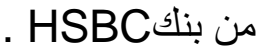

|I - II المحور الثالث: الهندسة المالية الإسلامية وتجنب الأزمات المالية

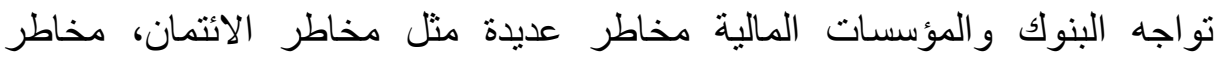




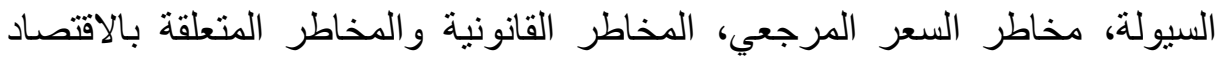

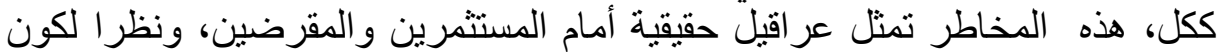

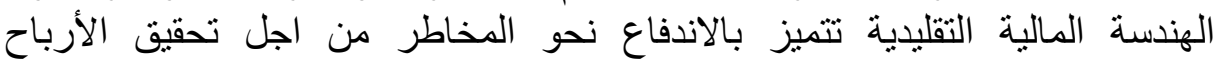

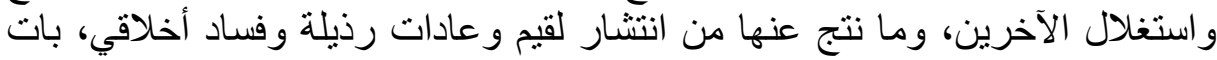

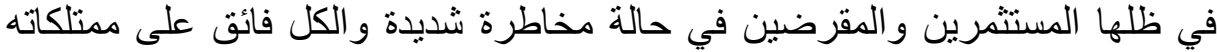
و أَصوله المالية، وما الأزمة المالية العالمية منا ببعيد.

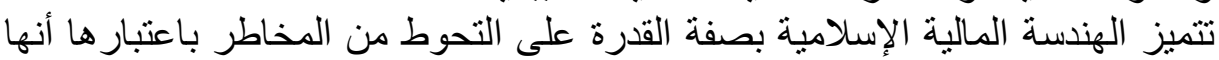

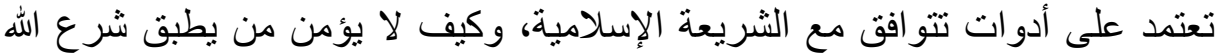

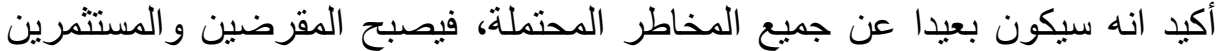
غير قلقين بشأن، ممتلكاتهح.

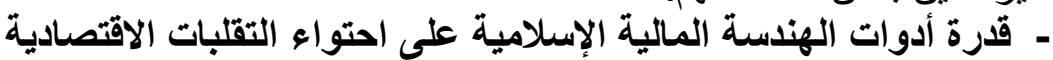

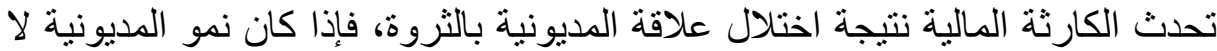

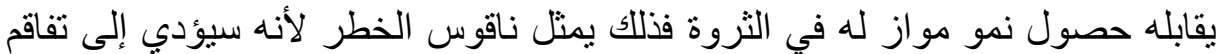

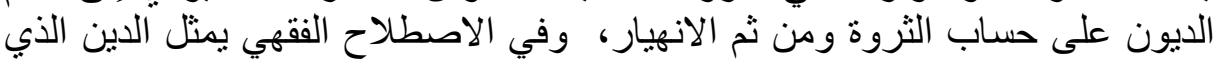

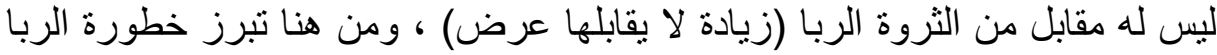

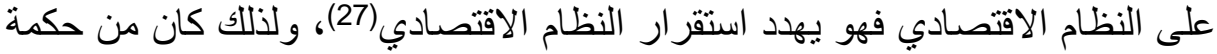

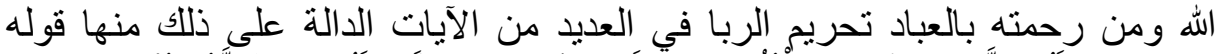

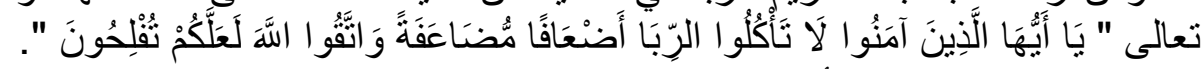

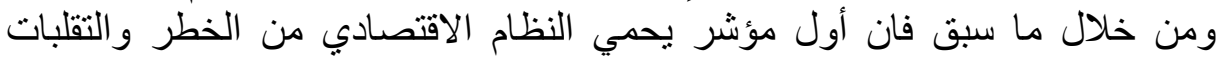

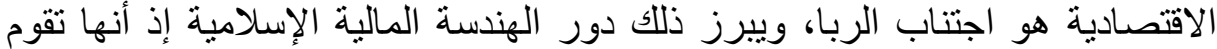

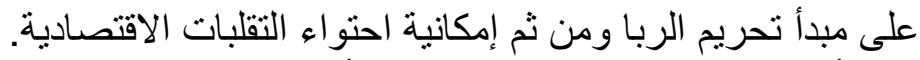

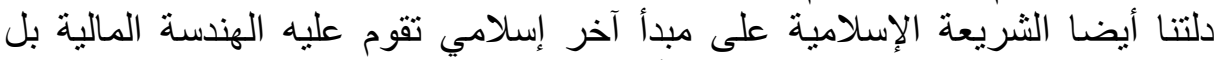

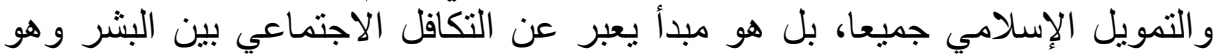

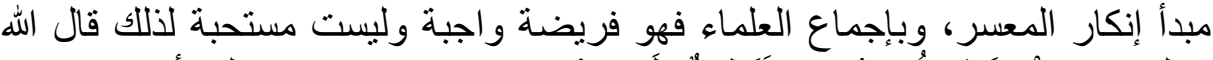

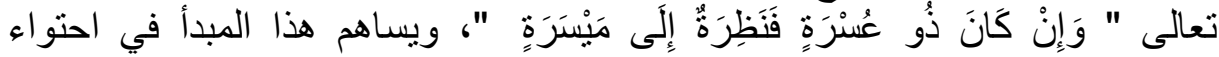

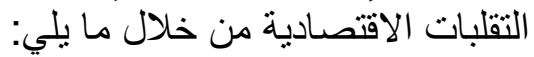

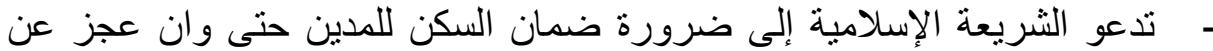

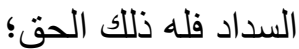

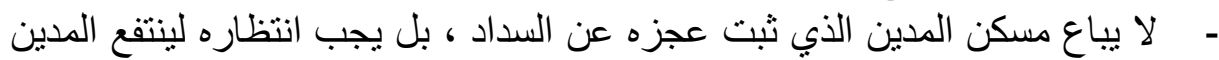

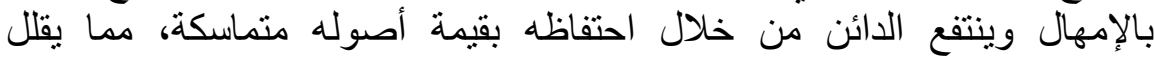

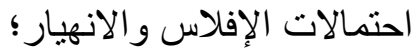
- يكون الدائن أكثر حذرا في منح الائتمان إذا علم مسبقا انه لن يسنطيع الاسترباح

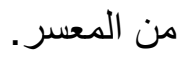

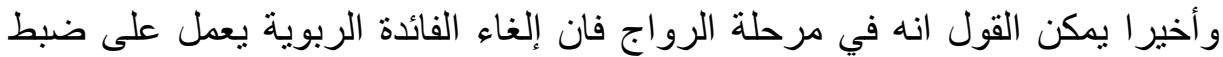

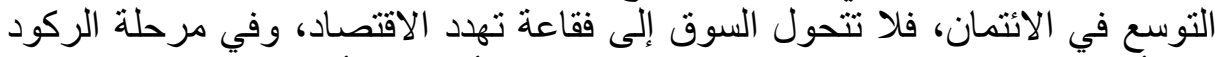

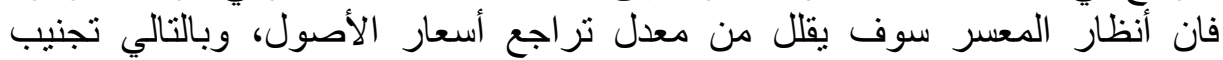

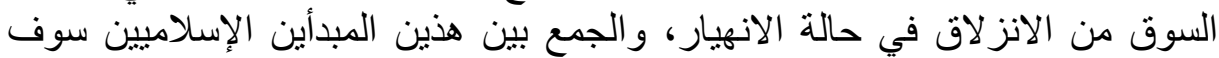

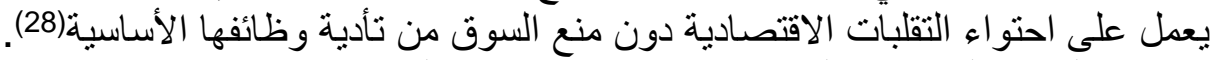

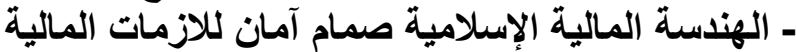

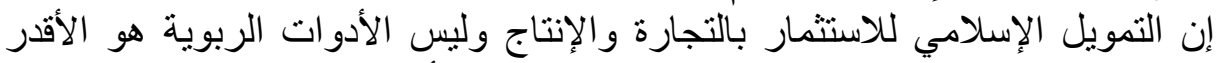

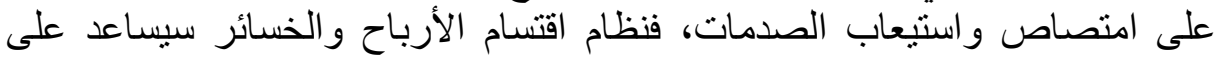

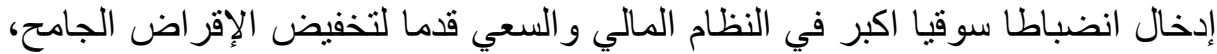

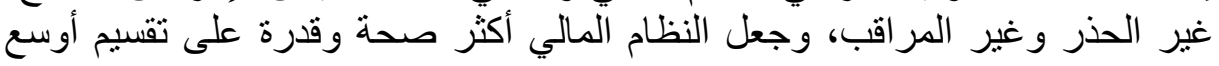




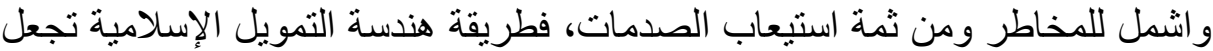

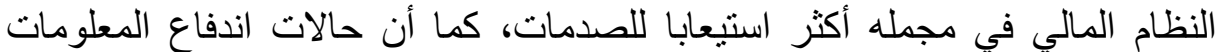

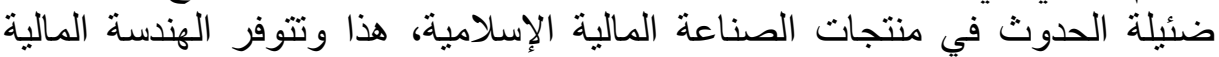
الإسلامية على مميزات وايجابيات لتجنب ومعالجة الأزمات المالية والمتمثلة في أسو اقها و أدو اتها المالية نذكر منها: أ.مميزات وايجابيات السوق المالية الإسلامية:

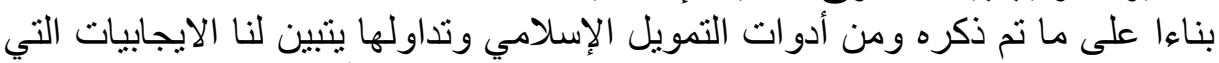

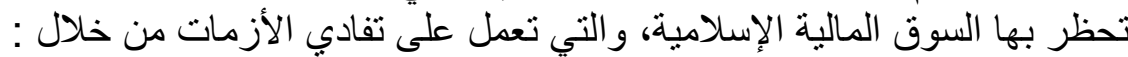

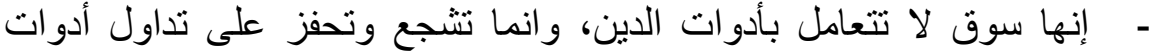

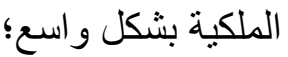

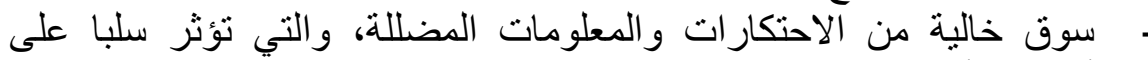
أسعار الأوراق المالية المتداولة فيها؛ - - يتم الاهتمام بالسوقين الأولية والثانوية بشكل متكافئ، ونعتبر آن معيار كفاءة

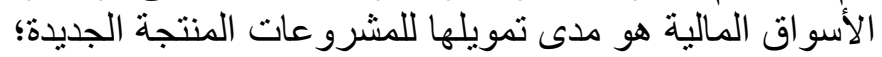

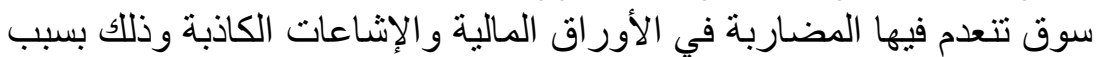

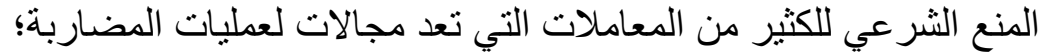

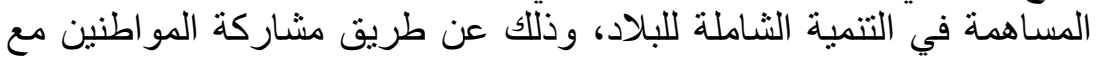
الدولة في مشرّو عاتها الإنمائية؛

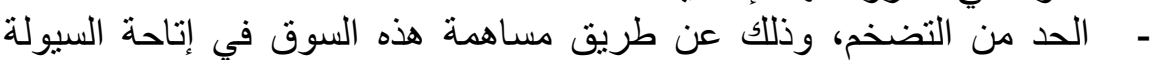
و التمويل طويل الآجل اللازمين لإيجاد فرص استثنمارية جديدة؛

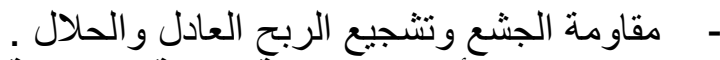

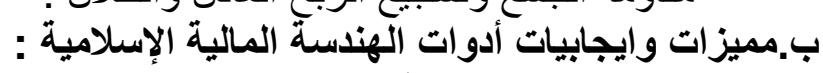

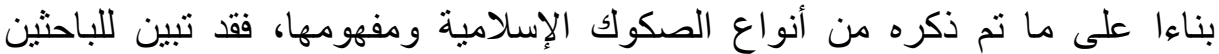
الايجابيات التي حظيت بها، والتي تؤدي إلى تفادي ومعالجة الأني الأزمات المالية نذكر منها: ـ الصكوك تمثل ملكية حصص شائعة في الموجودات، بعكس السندات الربوية التي

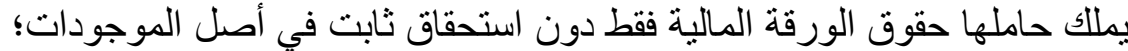

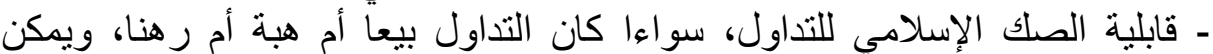

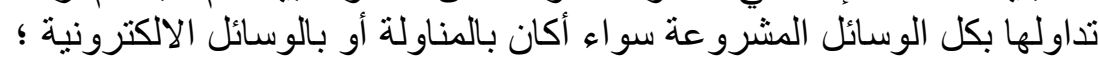

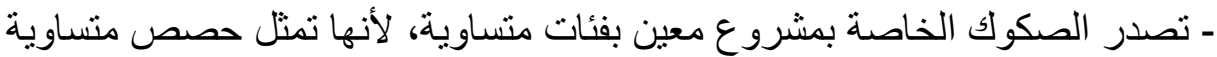

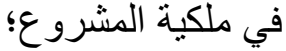
- ضبط الإصدار والتداول بضوع ابط شر عية، شانها شان كافة المعاملات المالية التي يجب أن تتم وفق القوار القد الثداول المالية الإسلامية؛ ـ تعمل الأدوات المالية الإسلامية على زئية الإدة الإدية التدفقات في الاستثمار ات الإسلامية الأمر الذي يؤدي إلى انفتاح سوق المال الإسلامية الإلى عالميا؛

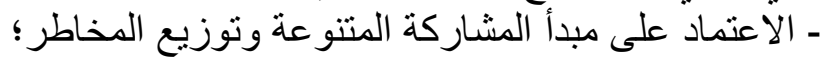

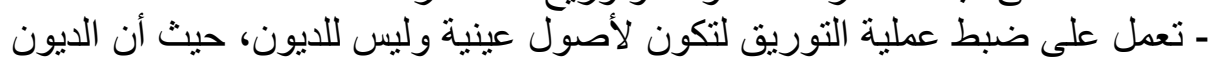

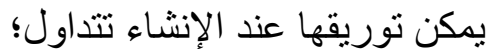

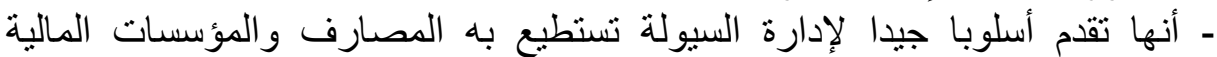

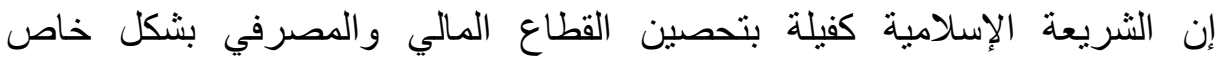
والاقتصاد بشكل عام من التعرض للازمات، إذا ما تم الالتزام بالثريعة بما تمثله من 
أسس ومفاهيم أخلاقية والتي تمثل القاعدة الفعالة لمنع الأزمات، حيث كانت ابرز

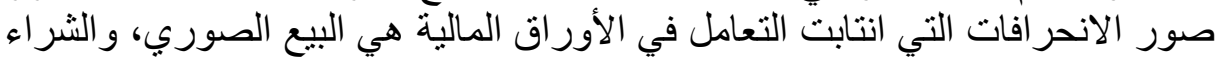

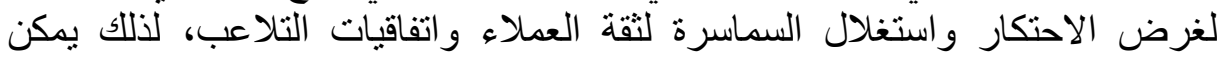

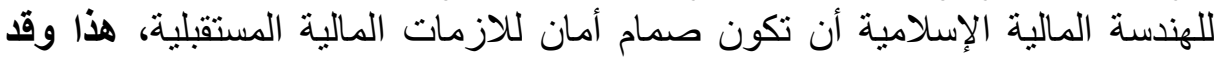
خلص البحث إلى النتائج التالية : الندان

- -

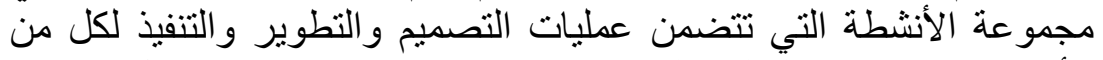

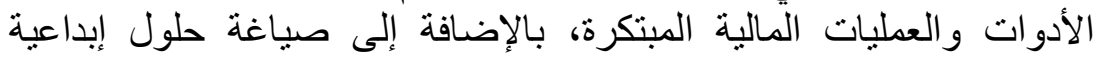
لمشاكل التمويل، وكل ذللك ضمن أحكام الثريعة الإسلامية؛ الإضئ

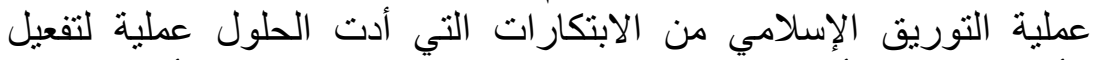

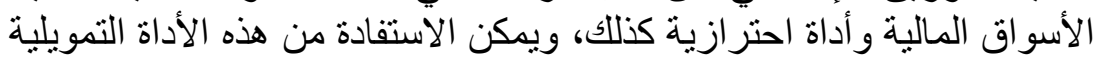

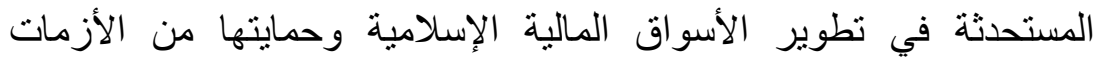

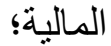
إن الهندسة المالية الإسلامية، تحتوي على تشكيلة متنوعة من الأدوات

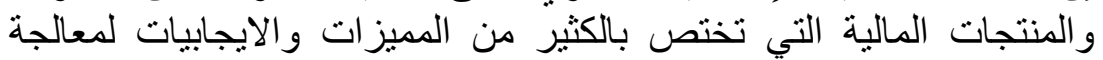
وتجنب الأزمات المالية؛ المالية - - يطرح النظام المالي الإسلامي العديد من المقترحات الفعالة المعالة لمعالجة الأزمة

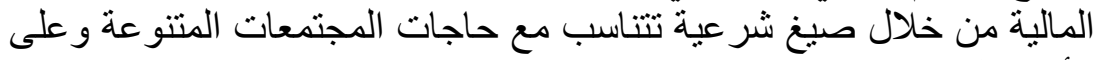

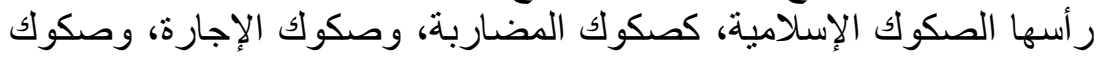

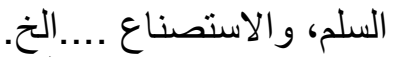

\section{ويمكن تلخيص توصيات البحث في النقاط التالية:}

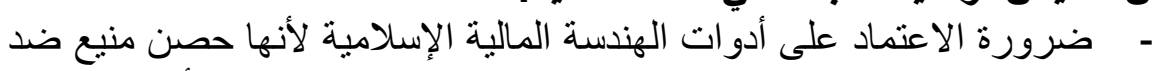

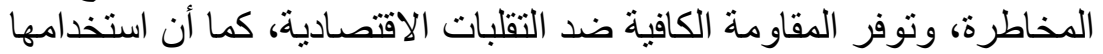

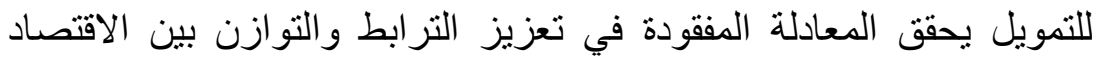

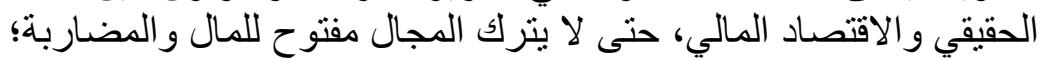

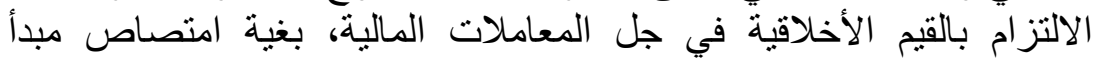
المادية، ومسحه من النفس البشرية؛

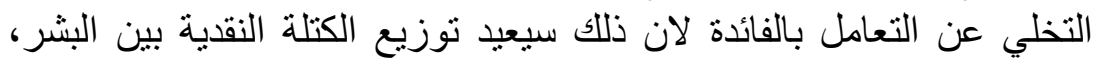

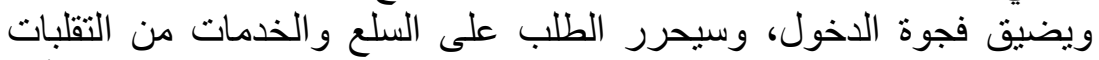

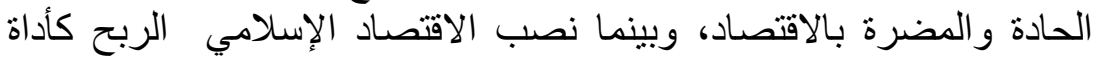

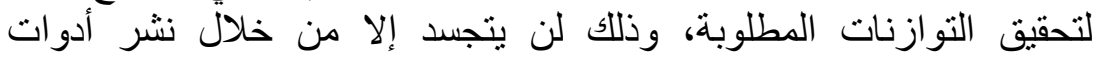

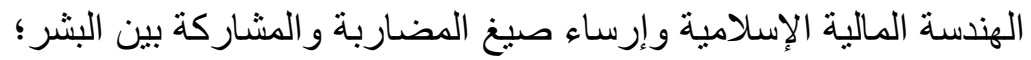

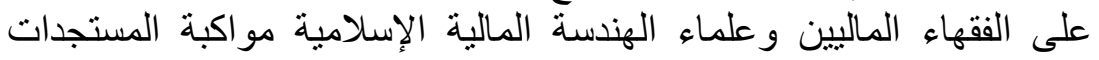

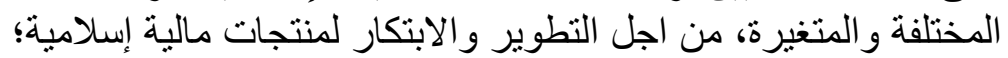

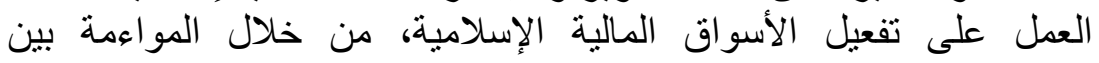
المصداقية الثر عية و الكفاءة الاقتصادية. 
الاحالات والمراجـ

عدنان فرحان الجوارني، الدورات الاقتصادية، مجلة الحوار المتمدن، العدد 3234،

2011/01/02

2) Kalasopatan Cynthia et Letondu français, les cycles économiques, revue problèmes économiques, $\mathrm{N}^{\circ}=2949$, juin 2008, P 41 بول سامويلسون، وليام د.نوردهاوس، الاقتصاد، ترجمة هشام عبد الله، الدار الأهلية للنشر

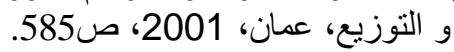

4) Beitone Alaine et autres, Analyse économique et historique des sociétés contemporaines, colin Armond, Paris, 1998, P 122

5) Aglietta Michel, Crises et Cycles Financiers, une Approche Comparative, Revue du CEPII, $n^{\circ} 05$, Octobre 1993,PP 3-4.

$$
\text { 690م، صمير أمين، الطبقة والأمة في التاريخ وفي مرحلة الإمبريالية، دار الطليعة، بيروت، }
$$

7) Shalck Christophe, Cycle de Mins Ky et Crises Financières du

19eme Siècle, présentation disponible sur internet, Université Paris, 19/12/2013, http:www.univ-orleans.fr/GDR recomofi/activ/schalk-nice.pdf

8) $\quad{ }^{1}$ Shalck Christophe, Opcit, PP 04-05.

محمد عبد الوهاب العز اوي، عبد السلام محمد خميسي، الأزمات المالية :قديمها و حديثها،

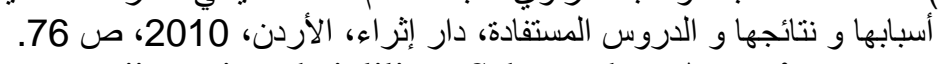

10) Barry jhonston, jingquing chai, liliana Schumacher, Assessing

financial system; vulnerability, IMF working paper London, April 2000, p07.

يوسف على عبد الأسدي، حسين جواد كاظم، تحلي لظاهرة الأزمةالمالية و سبب الإحاطة

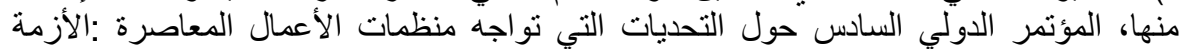

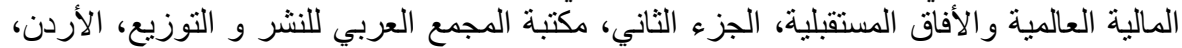

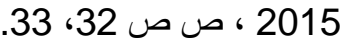

12) عبد النبي إسماعيل الطوفي، التتبؤ المبكر بالأزمات المالية باستخدام المؤشرات المالية

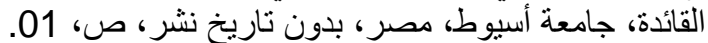

13) Burkat Olivier, les Crises de Change dans les pays émergents,

Bulletin de la banque de France, nº74, Février 2000, P 54.

أمال قحابرية، أسباب نثأة أزمة المديونية الخارجية للدول النامية، مجلة اقتصاديات شمال

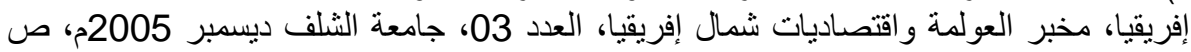

15)Boucher Christophe et Vasques Vincent, Les crises boursières aux Etats-

Unis détection et prévision, journées de recherche sur les crises

financières internationales, université d’Orléans, France, 6-7 mai 2004, p 03.

16)Fimmerty, Financial management , J.D Financial engineering in corporate finance (amoverview), vol 17, $\mathrm{N}^{\circ} 4,1988, \mathrm{p} 14$.

17) صالح فتح الرحمان علي، أدوات سوق النقد الإسلامي، مدخل للاندسة المالية الإسلامية،

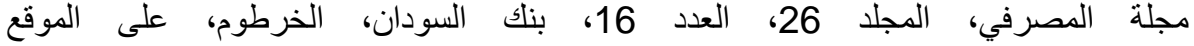

2018/02/20 بتاريخ اطلاع 16ww.kantakji.com

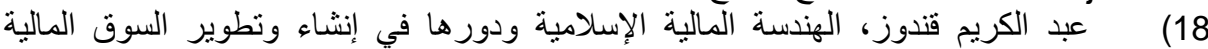

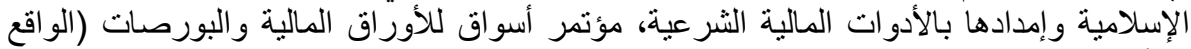

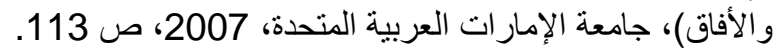

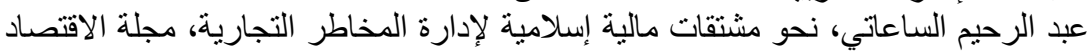

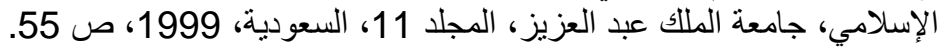

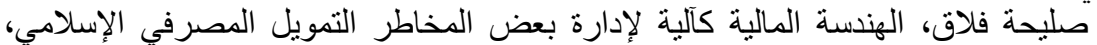

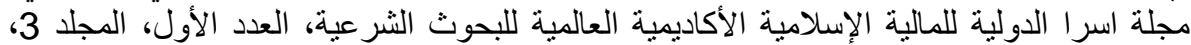

ماليزيا، يونيو 2012، ص ص صلالية 106-107. 


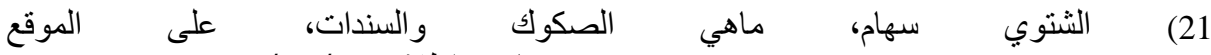

2018/02/23 بتاريخ اطلاع www.mutdawl.net/forns/showthread.php

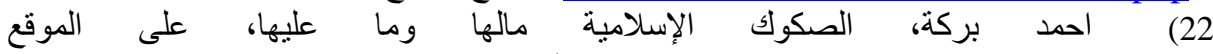

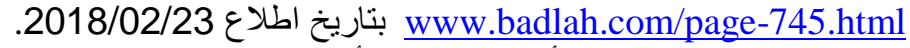

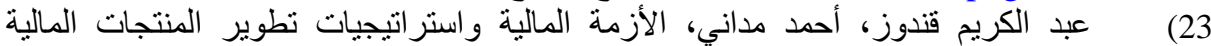

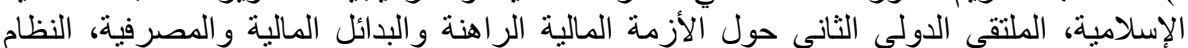

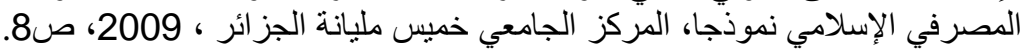

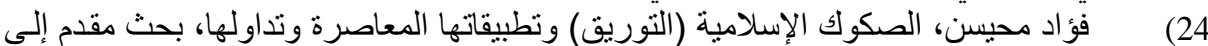

الدورة التاسعة عشر لمجمع الفقه الإسلامي الدولي، 16-30 الفريل

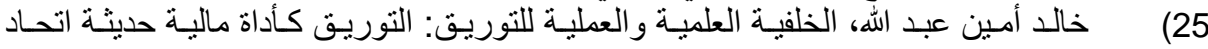

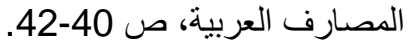

26) عبد العزيز الخياط، نظرية العقد والخيارات في الفقه الاسـلامي، المعهد العربي للاراسـات

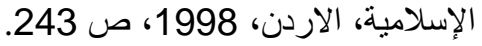

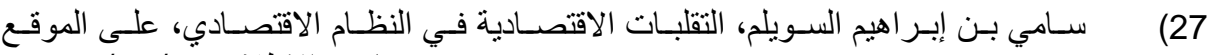

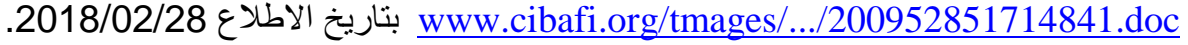

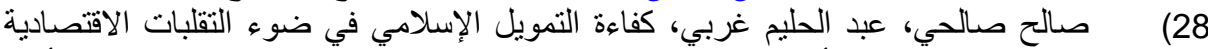

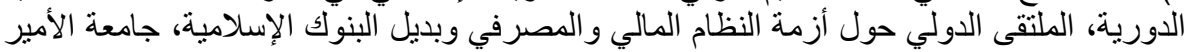

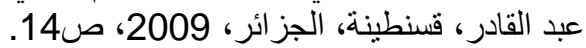

